\title{
OS EFEITOS DO CONTRATO INTERMITENTE NA CRIAÇÃO DE NOVOS POSTOS DE TRABALHO FORMAL: UMA ANÁLISE DE DADOS NO ESTADO DO CEARÁ
}

\author{
THE EFFECTS OF THE INTERMITTENT CONTRACT IN THE CREATION OF \\ NEW FORMAL EMPLOYMENTS: A DATA ANALYSIS IN THE STATE OF CEARÁ
} LOS EFECTOS DEL CONTRATO INTERMITENTE EN LA CREACIÓN DE NUEVOS
POSTOS DE TRABAJO FORMAL: UN ANÁLISIS DE DATOS EN EL ESTADO DEL
CEARÁ

\begin{abstract}
EduARdo RÉGIS GIRÃo de CASTRo PINTO https://orcid.org/0000-0001-6949-4940 / http://lattes.cnpq.br/8322517576164876 / eduardogirao@gmail.com Universidade de Fortaleza (UNIFOR).
\end{abstract} Fortaleza, CE, Brasil.

\author{
ANA ViRgínIA MOREIRA GOMES \\ https://orcid.org/0000-0001-6101-4965 / http://lattes.cnpq.br/3031062621468219 / avmgomes@gmail.com \\ Universidade de Fortaleza (UNIFOR). \\ Fortaleza, CE, Brasil.
}

\section{RESUMO}

Este estudo possui como objetivo a responder ao seguinte problema de pesquisa: é possível se argumentar que a oferta de contratos de trabalho intermitente favorece a formalização do trabalho? A pesquisa segue a abordagem qualitativa, por meio da revisão de literatura e, complementarmente, abordagem quantitativa, com base nas análises time series e cross-sectional, com periodização de novembro de 2017 a novembro de 2018, e como unidade de análise o Estado do Ceará. A base de dados é secundária e foi construída a partir de informações do Cadastro Geral de Empregados e Desempregados - CAGED, Portal do Ministério do Trabalho e do Emprego e Relatórios de Relação Anual de Informações Sociais - RAIS e Pesquisa Nacional por Amostra de Domicílios Contínua PNAD/ IBGE. Conclui-se que a adoção do contrato intermitente como estratégia de regulação do mercado de trabalho não resultou em um aumento significativo do número de postos de trabalho formal, evidenciando a falta de planejamento técnico da inovação normativa.

Palavras-chave: Contrato intermitente de trabalho; Reforma Trabalhista; Setor de Serviços.

\begin{abstract}
This paper aims to answer the following research problem: is it possible to argue that the offer of intermittent labor contracts favors the formalization of work? The research follows a qualitative approach, through literature review and, in addition, a quantitative approach based on temporal and transversal series, with periodization from November 2017 to November 2018, using as an unit of analysis the state of Ceará. The database is based on the General Register of Employed and Unemployed - CAGED, the Portal of the Ministry of Labor data, the Employment and Annual Relationship Reports of Social Information - RAIS and the National Survey by Sample of Continuing Households of PNAD / IBGE databases. The paper concludes that the use of the intermittent contract, as a strategy to regulate the labor market, did not result in a significant increase in the number of formal jobs, revealing the lack of technical planning for normative innovation.
\end{abstract}

Keywords: Intermittent work contract; Labor Reform; Service sector. 


\section{RESUMEN}

El presente estudio objectiva responder al siguiente problema de investigación: ¿es posible argumentar que la oferta de contratos de trabajo atípicos favorece la formalización del trabajo? La investigación sigue el abordaje cualitativo, a través de la revisión de literatura y, complementariamente, el enfoque cuantitativo, con base en los análisis time series y cross-sectional, con periodización de noviembre de 2017 a noviembre de 2018, y como unidad de análisis el Estado del Ceará. La base de datos es secundaria y fue construida a partir de informaciones del Catastro General de Empleados y Desempleados - CAGED, Portal del Ministerio de Trabajo y del Empleo e Informes de Relación Anual de Informaciones Sociales - RAIS e Investigación Nacional por Muestra de Domicilios Continua PNAD / IBGE. Se concluye que la utilización del contrato intermitente como estrategia de regulación del mercado de trabajo no resultó en un aumento significativo en el número de trabajos formales, evidenciando la falta de planificación técnica de la innovación normativa.

Palabras clave: Contrato intermitente de trabajo; Reforma Laboral; Sector de Servicios.

\section{SUMÁRIO}

INTRODUÇAO; 1 REFORMAS TRABALHISTAS: AS NOVAS CONFIGURAÇÕES DO CONTRATO DE TRABALHO; 2 CONTRATO INTERMITENTE: PROPOSTAS PARA A FORMALIZAÇÃO DO TRABALHO SOB DEMANDA; 3 ANÁLISE DE DADOS: O CONTRATO INTERMITENTE RESOLVEU O PROBLEMA?; CONCLUSÃO; REFERÊNCIAS.

\section{INTRODUÇÃO}

O estudo se propõe a responder ao seguinte problema de pesquisa: é possível se argumentar que a oferta de contratos de trabalho atípicos favorece a formalização do trabalho? A pesquisa examina essa questão ao analisar a evolução no saldo do emprego formal no setor de serviços a partir da introdução no ordenamento brasileiro do contrato de trabalho intermitente pela Lei $n^{\circ} 13.467 / 2017$. É possível se observar a evolução do saldo do emprego formal a partir da criação do contrato de trabalho intermitente pela Lei $n^{\circ}$ 13.467/2017 - Reforma Trabalhista, partir das razões que tendem a ser pauta da agenda política de elaboração e implementação de reformas trabalhistas no Século XXI.

A pesquisa analisa o conceito de contrato intermitente enquanto modelo para a formalização do trabalho sob demanda e os impactos na variação quantitativa do número de postos de trabalho no mercado brasileiro. Finalmente, o estudo reflete acerca da proteção da dignidade do trabalho como mandamento constitucional, cuja proteção deve ser multissetorial e articulada com a ideia de desenvolvimento.

$\mathrm{O}$ artigo se divide em três tópicos. O primeiro tópico aborda a reforma trabalhista de 2017 e as novas configurações do contrato de trabalho no Brasil, a partir da contextualização da agenda política de elaboração e implementação de reformas trabalhistas no Século XXI, da abordagem sobre o processo político de aprovação legislativa, e, finalmente, as razões pelas quais certos temas ingressaram na agenda pública brasileira (formalizar ou precarizar?). 
ISSN 1981-3694

(DOI): $10.5902 / 1981369436822$

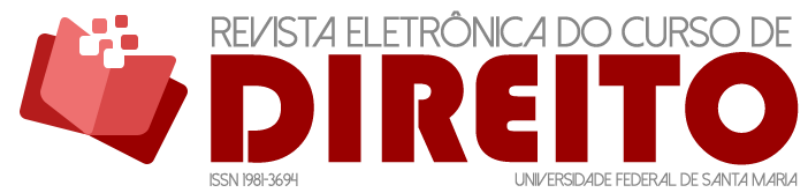

OS EFEITOS DO CONTRATO INTERMITENTE NA CRIAÇÃO DE NOVOS POSTOS DE TRABALHO FORMAL: UMA ANÁLISE DE DADOS NO ESTADO DO CEARÁ

EduARdo RÉGIS GIRÃo de CASTRO PINTO ANA VIRGÍNIA MOREIRA GOMES

0 segundo tópico se refere ao contrato intermitente enquanto modelo para a formalização do trabalho sob demanda, e à identificação de vantagens e desvantagens na perspectiva da promoção do aumento do número de postos e da proteção da dignidade do trabalho. Considerando-se que a principal motivação apontada na justificativa para a introdução do novo tipo contratual seria a criação de novos postos de trabalho para reduzir o índice de desemprego e informalidade no Brasil.

O terceiro tópico possui uma abordagem empírica, o que ocorre por meio da análise de informações pela técnica time series de coleta de dados, destinando-se a responder ao problema de pesquisa formulado. Os dados foram coletados a partir dos relatórios do CAGED, do Ministério do Trabalho e da RAIS, utilizando como metodologia a análise observacional cruzada com temporal e cross-sectional.

Esta pesquisa possui abordagem qualitativa, que consiste na análise interpretativa dos conceitos expostos, correlacionando-os ao fenômeno estudado e possibilitando a avaliação com foco no caráter subjetivo do objeto, averiguando a dimensão de suas particularidades. A escolha da pesquisa qualitativa como metodologia de investigação se sustenta na necessidade de avaliar teorias polissêmicas e definições para o tema em desenvolvimento, conferindo suporte teórico, documental e doutrinário para as proposições e permitindo a construção de inferências válidas a partir da análise acurada de textos com balizamento científico, propiciando um importante caminho para o acesso às informações desejadas e consequente fortalecimento do conhecimento acadêmico.

Ainda, o estudo possui abordagem com base em ferramentas econométricas como mecanismo complementar, conferindo robustez às explicações teóricas e sustentação causal para a formulação de inferências válidas. Considerando que o fator tempo é relevante para quase todo tipo de análise, assim como a comparação entre eventos, tal ferramenta evidencia vantagens epistemológicas para a pesquisa, na medida em que permite um olhar contínuo sobre a ocorrência dos fatos de maneira linear.

A periodização escolhida se concentrou na coleta de dados entre novembro de 2017 e novembro de 2018, e as análises propõem uma visualização parcimoniosa do problema em apreço. 0 período de recorte tem seu marco inicial justificado pela data da reforma trabalhista e, o marco final, se justifica pelo encerramento da fase de pesquisa e coleta propostas. A pesquisa é parcimoniosa porque, a partir de um período bastante específico de tempo, em que consideráveis modificações se precipitam quanto ao trabalho formal e informal, entende-se que 
ISSN 1981-3694

(DOI): $10.5902 / 1981369436822$

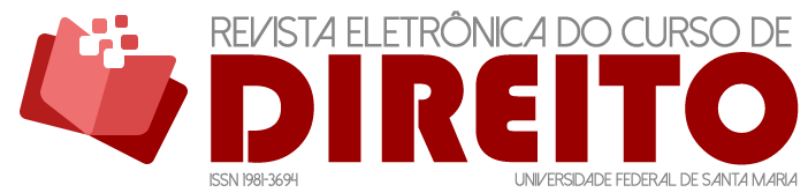

OS EFEITOS DO CONTRATO INTERMITENTE NA CRIAÇÃO DE NOVOS POSTOS DE TRABALHO FORMAL: UMA ANÁLISE DE DADOS NO ESTADO DO CEARÁ

EduARdo RÉGIS GirÃo de CASTRO PINTO ANA VIRGÍNIA MOREIRA GOMES

a amostra é representativa para gerar conclusões de médio alcance em relação à dinâmica de empregabilidade.

A modalidade de pesquisa escolhida, também em obediência à discricionariedade e parciomoniosidade do estudo, consiste em análise quali-quanti, com base em abordagem observacional, pura e que opta pelo uso de dados secundários, justamente para valorizar a transparência das informações obtidas e a validação na elaboração das inferências, garantindo assim a futura replicabilidade. A partir da aplicação da técnica análise de séries temporais (time series analysis) e análise cross-sectional, verifica-se o desenvolvimento do problema ao longo do tempo, tornando possível o exame quanto à evolução ou involução da questão tratada em um período específico.

A técnica se mostrou adequada porque permite a pesquisa sobre o comportamento dos dados coletados ao longo do tempo, permitindo uma visualização linear e progressiva do objeto de estudo. A base de dados é secundária e foi construída a partir de informações do Cadastro Geral de Empregados e Desempregados - CAGED, Portal do Ministério do Trabalho e do Emprego e Relatórios de Relação Anual de Informações Sociais - RAIS e Pesquisa Nacional por Amostra de Domicílios Contínua PNAD/ IBGE.

Sob o aspecto teórico, o presente artigo é relevante porque oferece uma contribuição original e inédita sobre os efeitos da Reforma Trabalhista e adoção do contrato intermitente nos indicadores de desemprego no mercado de trabalho formal, especialmente no setor de serviços, no âmbito do Estado do Ceará. Este foi escolhido como foco da pesquisa por fazer parte de um estudo que pretende a visualização de um problema com impactos locais a serem conhecidos e por se tratar de uma unidade federativa com crescimento econômico correspondente ao dobro da economia nacional no segundo trimestre de 2019, evidenciando performance econômica relevante, conforme indicadores do Instituto Brasileiro de Estatística e Geografia - IBGE 2019 e Instituto de Pesquisa e Estratégia Econômica do Ceará (Ipece), representando uma região capaz de ser comparada às demais regiões do país em nível de criação de vagas formais de emprego.

Quanto ao ponto de vista prático, o estudo se destina a verificar se a criação de uma estratégia de regulação do mercado de trabalho baseada apenas em modelos formais pode efetivamente surtir efeitos. 


\section{REFORMAS TRABALHISTAS: AS NOVAS CONFIGURAÇÕES DO CONTRATO DE TRABALHO}

A reforma trabalhista de 2017, realizada no Brasil, é marcada por polêmicas e controvérsias desde a sua concepção. 0 primeiro problema apontado é o déficit de legitimidade do governo Temer, iniciado em razão do controverso impeachment da Presidente Dilma Rousseff pela suposta prática de irregularidades fiscais (“pedaladas”) ${ }^{1}$. 0 segundo é o vício formal arguido em face da falta de participação efetiva dos trabalhadores no debate, no processo democrático de construção e tramitação da proposta, conforme determina a Convenção $\mathrm{n}^{\circ} 144$ da Organização Internacional do Trabalho (OIT), ratificada pelo Estado Brasileiro, sobre consultas tripartites para promover a aplicação das normas internacionais do trabalho.

Essa norma internacional prevê a necessidade de diálogo entre as representações dos trabalhadores e dos empregadores e os Estados quando da apresentação de propostas que versem sobre temas dispostos em convenções e recomendações da OIT. Por exemplo, a Lei 13.467/2017 incluiu na CLT os artigos 611-A e 611-B alterando a função e os objetivos da negociação coletiva em desconformidade com a Convenção 98, 151 e 154 da OIT, todas ratificadas pelo Brasil. ${ }^{2}$

$\mathrm{Na}$ visão da Associação Nacional dos Procuradores do Trabalho - ANPT, da Associação Nacional dos Magistrados da Justiça do Trabalho - ANAMATRA, da Associação Nacional dos Membros do Ministério Público - CONAMP, da Associação dos Magistrados Brasileiros - AMB, da Associação dos Juízes Federais do Brasil - AJUFE, da Associação do Ministério Público do Distrito Federal e Territórios - AMPDFT, da Associação dos Magistrados do Distrito Federal e Territórios (AMAGIS-DF), e da Associação Nacional do Ministério Publico Militar - ANMPM, entidades de classe de âmbito nacional que congregam mais de 40.000 juízes e membros do Ministério Público, ${ }^{3}$ não houve efetiva participação das representações dos trabalhadores durante a análise do PLC n $38 / 2017$.

\footnotetext{
${ }_{1}$ CASTRO, Rakel de; NASCIMENTO, José Shirley Pessoa do; SANTOS, Francisca Izabel A. dos. Reforma da previdência e trabalhista no Brasil: A democracia midiatizada no pós-impeachment de 2016. Estudos em Comunicação, 2018, n. 26, v. 2, p. 273-287.

${ }^{2}$ Ver ILO, Committee of Experts, 2018.

${ }^{3}$ Pedido conjunto de veto total ou parcial ao Projeto de Lei Da Câmara (PLC) $n^{\circ} 38$, de 2017, que resultou na aprovação e promulgação da Lei no 13.467/2017, de 13 de julho de 2017, a reforma trabalhista.
} 
ISSN 1981-3694

(DOI): $10.5902 / 1981369436822$

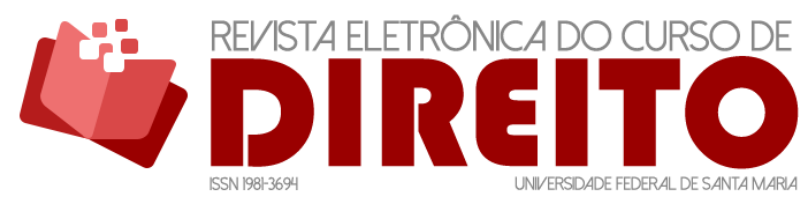

OS EFEITOS DO CONTRATO INTERMITENTE NA CRIAÇÃO DE NOVOS POSTOS DE TRABALHO FORMAL: UMA ANÁLISE DE DADOS NO ESTADO DO CEARÁ

EduARdo RÉGIS GIRÃo de CASTRO PINTO ANA VIRGÍNIA MOREIRA GOMES

De acordo com o pedido conjunto de veto, as casas legislativas "praticamente não acataram quaisquer das inúmeras ponderações e sugestões feitas por estas e outras entidades e instituições, incluindo em seu relatório inúmeras normas que prejudicam os trabalhadores e retiram direitos". Na hipótese, as entidades signatárias do pedido conjunto de veto apontam que a democracia não se mensura pelo número formal de audiências ou reuniões, mas na verificação de contraditório substancial, com o poder de voz dos trabalhadores sendo levado a sério nos processos decisórios, tal como previsto na Convenção $n^{\circ} 144$ da OIT.

A respeito do assunto, Gomes e Prado afirmam o entrelaçamento entre a liberdade de associação e democracia porque ambas compartilham as mesmas raízes: liberdade, autonomia, pluralismo e voz nos processos decisórios. Por isso, "estas liberdades fundamentais não podem ser suprimidas em uma esfera e florescer outro. Nesse sentido, a OIT entende a liberdade de associação como um dos elementos constitutivos de uma sociedade democrática" ${ }^{4}$. Por esses motivos, entende-se, ao lado das referidas instituições, que a proposta de Reforma Trabalhista padece do vício de inconvencionalidade.

O terceiro é o conjunto de violações materiais à Constituição Federal de 1988, apontadas por entidades de classe e pela doutrina. A constitucionalidade da Lei $\mathrm{n}^{\circ}$ 13.467/2017 é questionada em mais de 20 ações diretas de inconstitucionalidade; ${ }^{5}$ desse total, ao menos quatro (ADIs 6154, 5.806, 5.826, 5.829 e 5.950) impugnam a formalização do contrato intermitente, objeto da presente investigação. ${ }^{6}$

Este estudo, todavia, examina a reforma trabalhista (ou sua justificativa) a partir de outro paradigma, qual seja a compreensão da regulação do trabalho no contexto do desenvolvimento econômico e sustentável. Incluir a regulação do contrato de trabalho como objeto de atenção do Estado significa atender a um mandamento constitucional, relevante pela natureza de norma fundamental. E inserir o tema como objeto de regulação, sem dúvida,

\footnotetext{
${ }^{4}$ GOMES, Ana Virginia Moreira; PRADO, Mariana Mota. Flawed freedom of association in Brazil: how unions can become an obstacle to meaningful reforms in the labor law system. Comparative Labor Law and Policy Journal, 2010, v. 32, p. 843-861; PINTO, Marcio Morena. La fundamentalidad de los derechos sociolaborales desde la perspectiva de la dignidad de la persona humana. Revista Eletrônica do Curso de Direito da UFSM, Santa Maria, RS, ago. 2016, v. 11, n. 2, p. 576-600

${ }_{5}$ CONSULTOR JURÍDICO. OIT classifica reforma trabalhista brasileira como violadora de direitos. Disponível em: https://www.conjur.com.br/2018-mai-29/brasil-entra-lista-suja-oit-causa-reformatrabalhista. Acesso em: 23 nov. 2018. Sobre o tema ver GOMES, Ana Virginia Moreira. What is Collective Bargaining for? Brazilian Labor Law Reforms under ilo Scrutiny. International Labor Rights Case Law journal. , v.5, p.47 - 51, 2019.

${ }^{6}$ COELHO, Gabriela. TST discutirá estabilidade de contrato de trabalho intermitente. Consultor Jurídico, 16 de setembro de 2018. Disponível em: https://www.conjur.com.br/2018-set-16/tst-discutiraestabilidade-contrato-trabalho-intermitente. Acesso em: 23 nov. 2018.
} 
ISSN 1981-3694

(DOI): $10.5902 / 1981369436822$

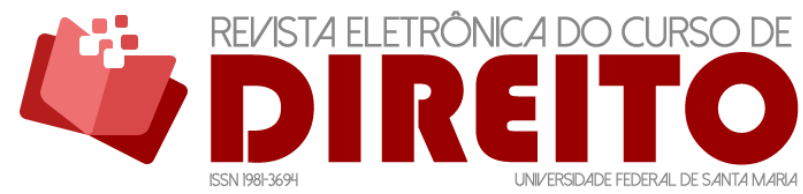

OS EFEITOS DO CONTRATO INTERMITENTE NA CRIAÇÃO DE NOVOS POSTOS DE TRABALHO FORMAL: UMA ANÁLISE DE DADOS NO ESTADO DO CEARÁ

EduARdo RÉGIS GIRÃo de CASTRO PINTO ANA VIRGÍNIA MOREIRA GOMES

corresponde a uma das mais necessárias iniciativas no contexto do mercado de trabalho brasileiro no Século XXI.

Isso porque o declínio do Estado-providência, ao lado da estagnação econômica, passou a orientar ajustes visando ao equilíbrio fiscal e à eficiência do aparelho burocrático do Estado. ${ }^{7}$ As primeiras ações desenhadas para alcançar os referidos objetivos consistiram em intervenções para (1) revisão de benefícios sociais, notadamente relacionados à aposentadoria; e (2) afrouxar os regimes regulatórios da relação de trabalho a fim de promover maior competitividade econômica, flexibilidade no mercado de trabalho e crescimento do emprego. ${ }^{8}$

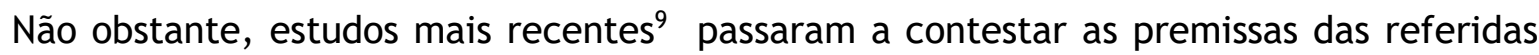
ações ou reformas acima descritas, defendendo (1) uma concepção de desenvolvimento mais ampla, contemplando não somente o crescimento do PIB, mas também o avanço do desenvolvimento humano; ${ }^{10}$ (2) a falta de base empírica da associação generalizante entre desregulação da relação de trabalho e aumento da competitividade econômica sem levar em consideração inovações tecnológicas e peculiaridades regionais ou setoriais.

A partir das críticas e estudos apresentados, esse segundo grupo de autores sustentou o desenvolvimento de ações ou reformas fincadas em premissas como; (1) regulação inteligente, empiricamente apoiada em diagnósticos regionais e setoriais do mercado de trabalho; e (2) uma visão sistêmica da legislação trabalhista e do desenvolvimento, aberta à experimentação e inovação em diferentes contextos nacionais e regionais, a partir da adoção de ampla e variada gama de técnicas regulatórias.

Nessa perspectiva, tomando como paradigma a crise de 2008-2009, Bensusán (2016) observa que "muitos países (19 dos 27 Estados-Membros da UE nessa altura) responderam à crise com novas reformas trabalhistas reduzindo direitos e cortando redes de segurança social; já outros (...) os ampliaram e fortaleceram sem comprometer a recuperação econômica".

\footnotetext{
7 FREITAS JR, Antônio Rodrigues de. 0 trabalho à procura de um direito: crise econômica, conflitos de classe e proteção social na Modernidade. Estudos avançados, 2014, v. 28, n. 81, p. 69-93.

8 KAUFMAN, Bruce Evan, Labor Law and Employment Regulation: Neoclassical and Institutional Perspectives (July 2008). Andrew Young School of Policy Studies Research Paper No. 08-27

9 KOLBEN, Kevin et al. Labour regulation, capabilities, and democracy. Labour regulation and development: Socio-legal perspectives, 2016, p. 60-81; LANGILLE, Brian. Imagining Post "Geneva Consensus" Labor Law for Post "Washington Consensus" Development. Comparative Labor Law and Policy Journal, 2009, v. 31, p. 523-531; TREU, Tiziano. Labour law and sustainable development. In: Labour Law and Social Security in the Americas: 10th American Regional Congress of the International Society for Labour and Social Security law. G Giappichelli Editore, 2018; VERMA, Anil. Labour Regulation and Jurisdictional Competitiveness, Investment, and Business Formation: A Review of the Mechanisms and Evidence. Toronto: Ontario Ministry of Labour, 2016.

${ }^{10}$ DEAKIN, Simon. The Capability Approach and the Economics of Labour Law. The Capability Approach to Labour Law, 2019, p. 147.
} 
ISSN 1981-3694

(DOI): $10.5902 / 1981369436822$

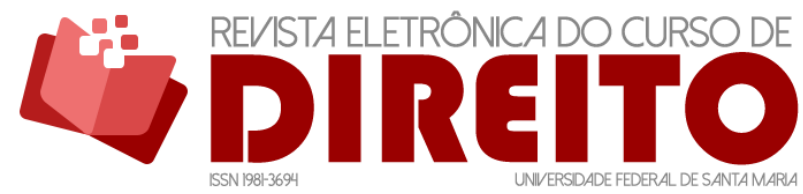

OS EFEITOS DO CONTRATO INTERMITENTE NA CRIAÇÃO DE NOVOS POSTOS DE TRABALHO FORMAL: UMA ANÁLISE DE DADOS NO ESTADO DO CEARÁ

EduARdo RÉGIS GirÃo de CASTRO PINTO ANA VIRGÍNIA MOREIRA GOMES

Especificamente, no caso da Inglaterra - um dos países nos quais se permite o contrato de trabalho zero-hora -, Koumenta e Williams (2018) relacionam reformas flexibilizadoras, reconhecimento jurídico de contratos atípicos e precariedade.

As autoras explicam que a "estratégia regulatória do Estado de aumentar a flexibilidade no mercado de trabalho e de mudança da ênfase dos direitos coletivos para a proteção individual esteve (sob o governo Trabalhista) e permanece (sob o atual governo Conservador). Mesmo nesse contexto, o Estado não conseguiu estender todo o escopo dos direitos individuais aos trabalhadores com contratos flexíveis, implicando no já bem documentado aumento do trabalho inseguro e da precariedade".

É interessante observar que no caso da Inglaterra (zero-hours contract) ${ }^{11}$, Estados Unidos e Canadá (“just-in-time scheduling” contracts), e Irlanda ("if and when" contracts), o zero-hora contrato não foi introduzido por uma legislação específica, "mas pelas próprias empresas ao forçarem a compreensão que não era necessário fornecer um mínimo de horas garantidas aos trabalhadores em um contrato de trabalho" (ILO, 2016). Por certo, esse tipo de entendimento prevalece em contextos econômico, político e jurídico desfavoráveis a garantias de proteção ao trabalho.

Analisando a América Latina, à luz de estudos comparativos sobre as variedades do capitalismo e seus arranjos institucionais, Bensusán (2016) identifica padrões impeditivos de melhor desempenho econômico e social nos mercados latino-americanos durante as recentes décadas: baixos níveis de qualificação, regulações de alto nível, alta rotatividade de mão-deobra, setor informal generalizado e sindicatos que, embora politizados, eram pouco presentes no local de trabalho e tinham limitado poder de negociação.

No caso da reforma trabalhista efetivada no Brasil em 2017, com a aprovação da Lei ${ }^{\circ}$ 13.467/2017, de 13 de julho de 2017, essa parece estar sintonizada com a revisão de benefícios sociais e o afrouxamento da legislação trabalhista em busca de competitividade econômica e geração de empregos, o que se pode concluir a partir da exposição de motivos da MP $\mathrm{n}^{\circ}$ $808 / 2017^{12}$ e do voto do relator Rogério Marinho ${ }^{13}$ durante a tramitação do projeto de lei da

$11 \mathrm{Na}$ Inglaterra, em 2015, o Small Business, Enterprise and Employment Act 2015 introduziu os artigos 27(A) e 27(B) no Employment Rights Act de 1996

12 Exposição de Motivos da Medida Provisória $\mathrm{n}^{\circ}$ 808/2017. Disponível em: http://www.planalto.gov.br/ccivil_03/_Ato2015-2018/2017/Exm/Exm-MP-808-17.pdf. Acesso em: 30 nov. 2018.

${ }^{13}$ Parecer do Relator apresentado na Comissão Especial do Projeto de Lei $n^{\circ}$ 6.787/2016. Comissão Especial Destinada a Proferir Parecer ao Projeto de Lei n ${ }^{\circ}$ 6.787/2016. Relator: Deputado Rogério Marinho. 
reforma trabalhista. Nesse sentido, a regulação do contrato de trabalho e a oferta de contratos de trabalhos atípicos constituem pontos centrais dessa proposta. ${ }^{14}$

\section{CONTRATO INTERMITENTE: PROPOSTAS PARA A FORMALIZAÇÃO DO TRABALHO SOB DEMANDA}

Inicialmente, é necessário enfrentar algumas questões referentes ao desenho do contrato de trabalho; como a eventual incerteza quanto ao ambiente em que serão exercidas as atividades laborais, a existência de assimetria nas informações sobre as funções que serão desempenhadas pelo trabalhador, e quais são as expectativas da instituição empregadora para com o contratado. Assim, quando uma relação de trabalho é estabelecida e firmada por um contrato, empregador e empregado definem regras mínimas de adequação, gerando incentivos e obrigações proporcionais à complexidade de cada função.

O contrato de trabalho estipula limites e celebra um acordo de vontades, a partir dos quais uma pessoa física se compromete à prestação de um serviço. 0 contrato de trabalho típico é aquele por tempo indeterminado, entre duas partes, por jornada completa, atraindo para si o maior nível da proteção assegurada pela lei trabalhista. ${ }^{15}$ A OIT (2016) conceitua trabalho atípico como o trabalho fora de uma relação de emprego típica, isto é, o trabalho que não é “tempo integral, por tempo indeterminado, bem como parte de uma relação de trabalho subordinada e bilateral".

No ordenamento brasileiro anterior à reforma, os contratos atípicos se concentravam nas seguintes espécies: (1) contrato por tempo determinado, com duração prefixada, em que o funcionário sabe previamente, no momento da contratação, a data de sua dispensa e é aplicável em contratações de serviço com natureza típica de prazo determinado, transitório ou de experiência; (2) contrato de trabalho temporário, que visa ao atendimento a uma necessidade transitória de substituição ou complementação do quadro de pessoal; e (3) contrato de trabalho

\footnotetext{
${ }^{14}$ INTERNATIONAL LABOUR ORGANIZATION (ILO) (2016). Committee of Experts. Non-standard employment around the world: Understanding challenges, shaping prospects, International Labour Office - Geneva: ILO. Disponível em: http://www.ilo.org/wcmsp5/groups/public/---dgreports/---dcomm/--publ/documents/publication/wcms_534326.pdf. Acesso em: 9 set. 2018.

15 BARBOSA, Attila Magno e Silva; ORBEM, Juliani Veronezi. "Pejotização": precarização das relações de trabalho, das relações sociais e das relações humanas. Revista Eletrônica do Curso de Direito da UFSM, Santa Maria, RS, dez. 2015, v. 10, n. 2, p. 839-859.
} 
ISSN 1981-3694

(DOI): $10.5902 / 1981369436822$

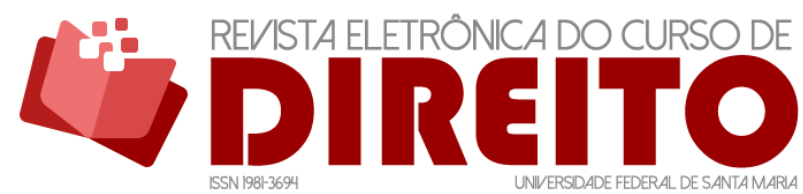

OS EFEITOS DO CONTRATO INTERMITENTE NA CRIAÇÃO DE NOVOS POSTOS DE TRABALHO FORMAL: UMA ANÁLISE DE DADOS NO ESTADO DO CEARÁ

EduARdo RÉGIS GIRÃo de CASTRO PINTO ANA VIRGÍNIA MOREIRA GOMES

por jornada parcial. ${ }^{16}$ Ademais, ressalta-se o trabalho terceirizado como o principal contrato atípico no mercado de trabalho brasileiro. Antes permitido somente em atividades meio, com as alterações na Lei $\mathrm{n}^{\circ} 6019 / 74$ promovidas pelas Leis $\mathrm{n}^{\circ} 13.429 / 2017$ e 13.467/2017, a terceirização passou a ser permitida em qualquer atividade da empresa.

A Lei no 13.467/2017, além de ampliar os contratos atípicos já previstos no ordenamento brasileiro, inclui uma nova modalidade: o contrato de trabalho intermitente. Esse contrato possui uma configuração diversa do contrato típico, na medida em que se apresenta como uma modalidade de contratação em que há subordinação não continuada e que se baseia na prestação de serviços de qualquer natureza entre períodos de inatividade. Pode-se conceituar o contrato de trabalho intermitente como o contrato de trabalho conforme o qual o empregador não garante ao indivíduo nenhuma quantidade mínima de horas de trabalho e o indivíduo não é obrigado a aceitar qualquer trabalho oferecido. ${ }^{17}$

Para as empresas e contratantes, há uma tendência à perspectiva de que a adoção dessa nova modalidade de contrato seja vantajosa, na medida em que há maior otimização das horas contratadas, visto que o profissional somente exercerá sua função em dias e horários definidos por demanda. Entretanto, para fins previdenciários, a contagem para atribuição do benefício se tornará ainda mais complexa e sujeita a falhas de registro, porque o cálculo recai sobre a integralidade das horas trabalhadas, sem contar o tempo de inatividade.

Destaque-se que a Reforma não definiu qual cálculo deveria ser adotado por empregados que porventura recebessem valor menor que 01 (um) salário mínimo por mês. Em razão do silêncio da norma, e dada a falta de especificação, a determinação realizada pela Receita Federal em 24 de novembro de 2017 foi que o trabalhador terá de complementar a contribuição ao INSS com rendimentos próprios. Tal medida se justifica porque o INSS desconsidera contribuições abaixo de $\mathrm{R} \$ 187,40$ (equivalente a 20\% do salário mínimo). Com o silêncio da norma, a Receita estipulou a regra. ${ }^{18} \mathrm{Em}$ acurada síntese, empregados regidos pelo contrato intermitente que percebem vencimentos inferiores a 01 (um) salário mínimo deverão

\footnotetext{
${ }^{16}$ MONTEIRO, N Joana C. M.; ASSUNÇÃO, Juliano J. Contratos de Trabalho nas microempresas no Brasil. Pesquisa e Planejamento Econômico. v. 39, n. 1, abr. 2009, p. 01-24.

17 KOUMENTA, Maria; WILLIAMS, Mark. An anatomy of zero-hour contracts in the UK. Industrial Relations Journal, 50:1, 2018, p. 20-40.

${ }^{18}$ Cf. Instrução Normativa RFB no 1867, de 25 de janeiro de 2019.
} 
ISSN 1981-3694

(DOI): $10.5902 / 1981369436822$

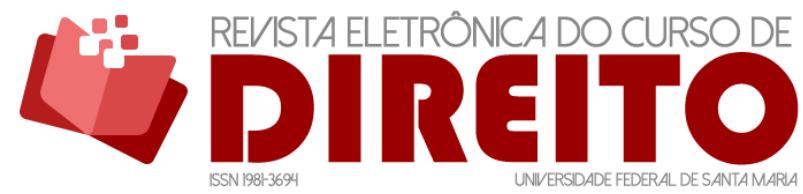

OS EFEITOS DO CONTRATO INTERMITENTE NA CRIAÇÃO DE NOVOS POSTOS DE TRABALHO FORMAL: UMA ANÁLISE DE DADOS NO ESTADO DO CEARÁ

EduARdo RÉGIS GIRÃo de CASTRO PINTO ANA VIRGÍNIA MOREIRA GOMES

contribuir para a Previdência o equivalente a $8 \%$ da diferença entre o salário recebido e o salário mínimo. ${ }^{19}$

Além das questões de ordem objetiva, não é possível olvidar a situação de temor contínuo do empregado, sobretudo em um período de crise de desemprego, diante da insegurança quanto a possíveis substituições por trabalhadores submetidos ao contrato intermitente. Ainda, o contrato intermitente pode ocasionar o "contrato zero hora" em que o empregado possui registro, mas pode não exercer seu ofício ou trabalhar, apenas quando chamado, sem qualquer garantia por uma renda mínima e quebrando o requisito da habitualidade. As consequências desse tipo de contrato na qualidade do emprego vêm sendo identificadas pela doutrina.

No contexto inglês, Felstead et al (2020) observam que a redução a curto prazo do número de horas a serem trabalhadas é duas vezes mais usual em contratos zero hora e o número de empregados preocupados com uma possível redução é três vezes maior que em outros contratos. Ademais, os autores constatam que a remuneração em contratos zero hora é mais baixa, enquanto a intensidade do trabalho, a ameaça de demissão e a rotatividade são mais altas. Nos contratos zero-hora, os trabalhadores se envolvem menos com a organização empregadora e o seu nível de bem-estar no trabalho é mais baixo.

Realidade semelhante se desenha no Brasil, como constatado pelo DIEESE (2020): “11\% dos vínculos intermitentes não geraram atividade ou renda em 2018 ”; “40\% dos vínculos que estavam ativos em dezembro de 2018 não registraram nenhuma atividade no mês. Ainda em dezembro, a remuneração foi inferior a um salário mínimo em $43 \%$ dos vínculos intermitentes que registraram trabalho.

Ao final de 2018, a remuneração mensal média dos vínculos intermitentes foi de R\$ 763". Esses dados revelam um alto nível precariedade desse tipo de contrato. 0 vínculo gerado é inseguro e de baixa qualidade. A insegurança em relação às horas a serem trabalhadas e à possibilidade de redução da jornada a curto prazo, na prática, inviabilizam que o empregado trabalhe simultaneamente para diferentes empregadores como forma de complementar a renda.

Sobre a criação de postos de trabalho, considerando a periodização do estudo, importa assinalar:

${ }^{19}$ FLORES, Paulo. Como os contratos intermitentes devem afetar o mercado de trabalho. Disponível em: https:// www.nexojornal.com.br/expresso/2017/11/28/Como-os-contratos-intermitentes-devem-afetar-omercado-de-trabalho. Acesso em: 30 nov. 2018. 
Figura 1: Criação de Vagas de Trabalho Intermitente e Parcial (novembro de 2017 a novembro de 2018)
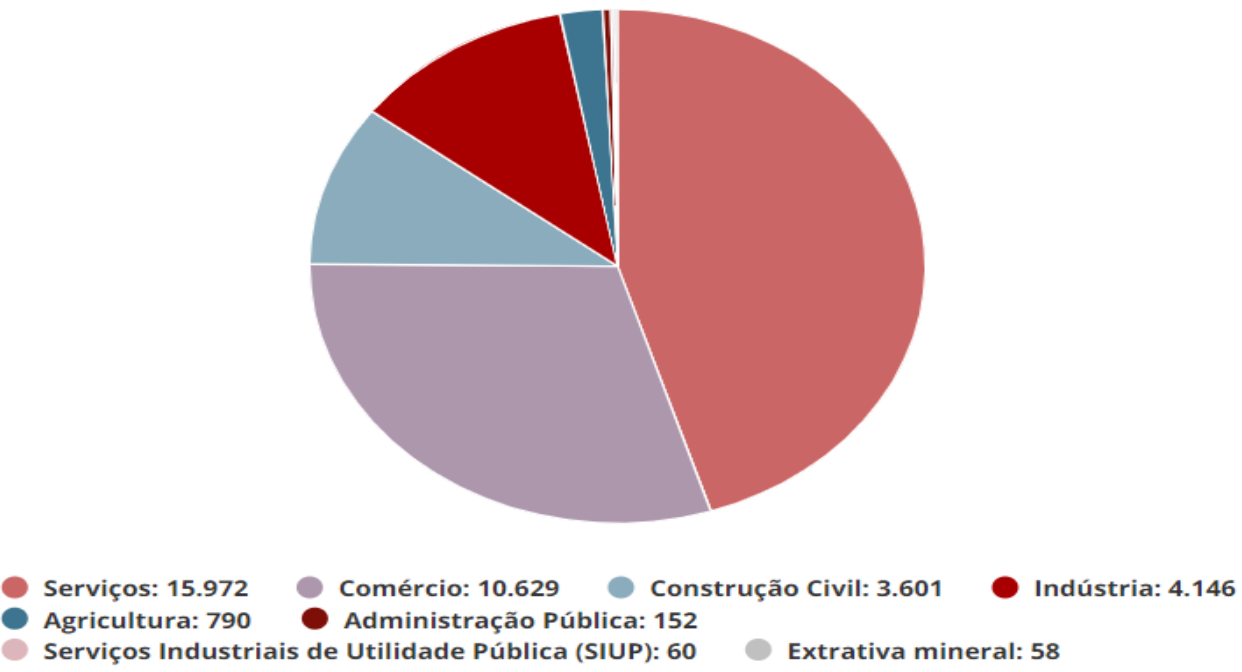

Fonte: Cadastro Geral de Empregados e Desempregados - CAGED, 2018. ${ }^{20}$

A Figura 1 evidencia que a introdução do contrato intermitente, a partir do momento da vigência da Reforma Trabalhista, gerou vagas de trabalho, pontualmente na área de serviços e comércio. Entretanto, o Cadastro Geral de Empregados e Desempregados - CAGED não especifica se houve efetivamente criação de postos de trabalho ou migração de outras áreas para os serviços e comércio ou de outras formas contratuais.

Se o índice de desemprego não diminuiu em números absolutos, aparentemente, pode ter havido substituição - por exemplo, de um empregado típico por um trabalhador intermitente - ou migração de entre áreas. De acordo com informações do CAGED, ${ }^{21}$ o setor de serviços lidera a criação de postos com base em contrato intermitente e em regime parcial, identificando a criação de mais de 8.500 vagas de trabalho intermitente e 7.400 vagas em regime parcial e que $45 \%$ das vagas foram apenas no setor de serviços.

Segundo dados do CAGED, ${ }^{22}$ para os postos de trabalho com contrato intermitente foram ocupadas vagas de assistente de vendas, recepcionista, alimentador de linha de produção, servente de obras, garçom, cozinheiro, faxineiro, pedreiro, carregador e vigilante. Para o regime de trabalho parcial, as vagas ocupadas corresponderam aos seguintes ramos: vendedor de

\footnotetext{
${ }^{20}$ BRASIL. Ministério do Trabalho. Cadastro Geral de Empregados e Desempregados - CAGED. Disponível em: http://trabalho.gov.br/trabalhador-caged. Acesso em: 29 nov. 2018.

21 BRASIL. Ministério do Trabalho. Cadastro Geral de Empregados e Desempregados - CAGED. Disponível em: http://trabalho.gov.br/trabalhador-caged. Acesso em: 29 nov. 2018.

22 BRASIL. Ministério do Trabalho. Cadastro Geral de Empregados e Desempregados - CAGED. Disponível em: http://trabalho.gov.br/trabalhador-caged. Acesso em: 29 nov. 2018.
} 
ISSN 1981-3694

(DOI): 10.5902/1981369436822

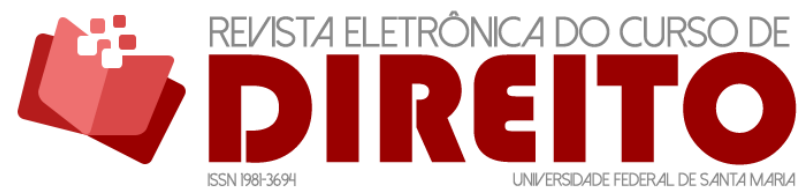

OS EFEITOS DO CONTRATO INTERMITENTE NA CRIACÃO DE NOVOS POSTOS DE TRABALHO FORMAL: UMA ANÁLISE DE DADOS NO ESTADO DO CEARÁ

EduARdo RÉGIS GIRÃo de CASTRO PINTO ANA VIRGÍNIA MOREIRA GOMES

comércio, assistente administrativo, repositor de mercadorias, operador de caixa, auxiliar de escritório, faxineiro, operador de telemarketing, recepcionista, motorista de ônibus e embalador. No período analisado, foram abertas mais de 30 mil vagas somente nessa modalidade, o que representa menos de $10 \%$ sobre o total de vagas criadas, conforme o gráfico a seguir:

Figura 2: Criação de Vagas de Trabalho Intermitente e Parcial em comparação às demais vagas criadas (novembro de 2017 a novembro de 2018)



Fonte: Cadastro Geral de Empregados e Desempregados - CAGED, 2018. ${ }^{23}$

É possível perceber uma inserção considerável do contrato intermitente e em regime parcial na abertura do número de vagas. Porém, seriam todas as vagas ocupadas por empregados no exercício de sua função? Importa assinalar que o Ministério do Trabalho contabiliza os trabalhadores regidos pelo contrato intermitente, porém, considerando que tal modalidade não possui como característica a habitualidade, é possível que a metodologia de coleta do Ministério do Trabalho tenha sido inadequada, incluindo pessoas que efetivamente não estão trabalhando.

No ponto, isso pode hipertrofiar os indicadores oficiais de emprego e obscurecer o resultado da coleta, levando a crer que a adoção do contrato intermitente gerou vagas quando, na verdade, pode ter apenas aumentado postos que não conduzem ao exercício profissional real (uma vez que é característica do contrato intermitente a relação não contínua e alternância de

${ }^{23}$ BRASIL. Ministério do Trabalho. Cadastro Geral de Empregados e Desempregados - CAGED. Disponível em: http://trabalho.gov.br/trabalhador-caged. Acesso em: 29 nov. 2018. 
ISSN 1981-3694

(DOI): 10.5902/1981369436822

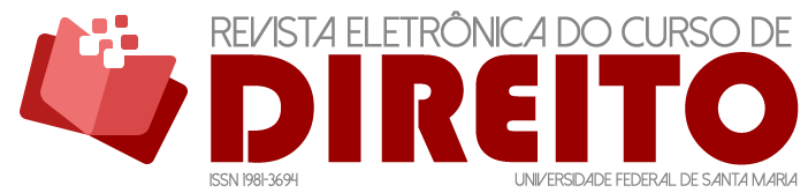

OS EFEITOS DO CONTRATO INTERMITENTE NA CRIAÇÃO DE NOVOS POSTOS DE TRABALHO FORMAL: UMA ANÁLISE DE DADOS NO ESTADO DO CEARÁ

EduARdo RÉGIS GIRÃo de CASTRO PINTO ANA VIRGÍNIA MOREIRA GOMES

períodos de trabalho e de inatividade), ou contabilizar como aumento do número de vagas a mera transição de um setor da economia para outro com menor nível de especialização.

\section{ANÁLISE DE DADOS: 0 CONTRATO INTERMITENTE RESOLVEU 0 PROBLEMA?}

Para se desenvolver uma abordagem empírica, é necessário coletar e analisar dados referentes ao fenômeno estudado, justamente para conferir maior robustez às teorias verificadas e fornecer explicações fiáveis que possam definir de maneira clara a correlação entre o problema de pesquisa e as respostas fornecidas pela reunião entre teoria e dados.

A teoria mobilizada para a pesquisa deve ser capaz de responder aos questionamentos do pesquisador de maneira ampla, sem espaços para análises subjetivas no que se refere à relação entre causa e efeito; mas é fundamental que haja elementos empíricos para fortalecer, confrontar ou mesmo testar as teorias. ${ }^{24}$

A clareza da modelagem também é necessária para conferir capacidade de replicabilidade, ou seja: a teoria deve ser testável e aplicável a situações concretas, e válida para estudos semelhantes, razão pela qual é necessário tornar transparentes os mecanismos de consulta, coleta e tratamento dos dados levantados, assim como sua relação com a teoria escolhida e eventuais correlações causais estabelecidas. Ainda, é importante ser preciso na escolha adequada das ferramentas metodológicas que são úteis ao processo de descoberta dessas correlações, justamente porque a coerência da pesquisa se sustenta na integração entre teoria utilizada, objetivos da pesquisa e meios hábeis à verificação e mensuração dos fenômenos.

Partindo do pressuposto de que o controle de experimentos é a base para a pesquisa científica, a seleção das ferramentas metodológicas é essencial para a obtenção de resultados, tanto sob o ponto de vista observacional quanto na esfera empírica. Considerando que a chave para estabelecer relações causais é a comparação, e que nem sempre um único tipo de abordagem é útil para as descobertas científicas, opta-se aqui pelo pluralismo metodológico; ou

${ }_{24}$ POPPER, Karl. The logic of scientific discovery. London, Routledge, 1995; EVERA, Stephen Van. Guide to methods for students of political Science. Ithaca: Cornell University Press, 1997. 
ISSN 1981-3694

(DOI): $10.5902 / 1981369436822$

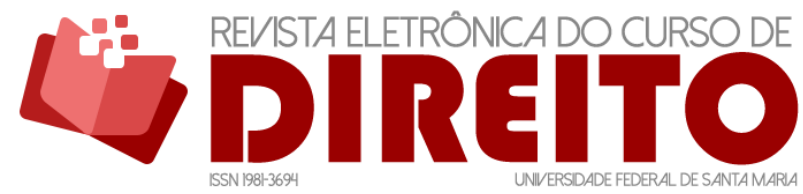

OS EFEITOS DO CONTRATO INTERMITENTE NA CRIAÇÃO DE NOVOS POSTOS DE TRABALHO FORMAL: UMA ANÁLISE DE DADOS NO ESTADO DO CEARÁ

EduARdo RÉGIS GIRÃo de CASTRO PINTO ANA VIRGÍNIA MOREIRA GOMES

seja, pela utilização de mais de uma ferramenta de investigação, reunindo elementos complementares para responder ao problema de pesquisa. ${ }^{25}$

Propõe-se a utilização de duas técnicas metodológicas observacionais na busca de respostas ao problema de pesquisa, ambas de origem econométrica: o cruzamento entre a análise observacional cross-sectional, que possui foco na variação entre unidades individuais e análise observacional time-series, que possui foco na variação em unidades agregadas através de um período determinado de tempo. ${ }^{26}$

A análise cross-sectional é útil porque se destina a examinar, de forma transversal, variáveis distintas como unidade de análise (Estado do Ceará), período de tempo definido e ocorrência de um fenômeno (no caso, a variação quantitativa do trabalho sob demanda a partir da adoção do contrato intermitente). Um estudo transversal deve ser representativo da população se as generalizações dos resultados forem válidas, ou seja, se as ferramentas metodológicas utilizadas forem claras. ${ }^{27}$

O objetivo dessa técnica é a mensuração simultânea das variáveis e verificação sobre a prevalência entre elas (qual seria a variável determinante entre o tempo, a unidade de análise e o fenômeno estudado, ou se é possível estabelecer uma mínima correlação entre essas variáveis para responder ao problema de pesquisa). O direito do trabalho ou a forma de regulação não constituem variáveis para o texto, primeiro, por não serem mensuráveis em um padrão categórico, segundo, porque se destacam como os institutos ou áreas que podem sofrer impacto com as formas de contratação e o número de empregos gerados, mas que não tendem a ser alterados em sua essência, na medida em que normas jurídicas possuem elevado grau de abstração justamente para adequada aplicação ao caso concreto e exige profunda análise normativa também sob aspectos periféricos e de alcance.

A análise de série temporal, ou time series analysis, consiste em uma técnica oriunda de estudos econométricos que se destina a realizar uma coleção de observações sobre a incidência de determinado evento em um período definido de tempo, para identificar a intensidade ou periodicidade de sua ocorrência, de forma sequencial no tempo (a variável tempo poderia ser

\footnotetext{
${ }^{25}$ REZENDE, Flávio da Cunha. A "nova metodologia qualitativa" e as condições essenciais de demarcação entre desenhos de pesquisa na ciência política comparada. Revista Política Hoje, 2011, v. 20, n. 1, p. 218 $-252$.

${ }^{26}$ RAO, T. Subba. Time Series Analysis. Journal of Time Series Analysis, 2009, v. 31, n. 2, p. 234-267.

27 SHUMWAY, Robert H.; STOFFER, David S. Time series analysis and its applications with R examples. London: Springer International Publishing AG, 2017.
} 
ISSN 1981-3694

(DOI): $10.5902 / 1981369436822$

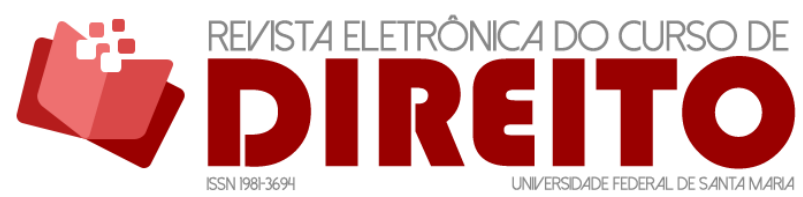

OS EFEITOS DO CONTRATO INTERMITENTE NA CRIAÇÃO DE NOVOS POSTOS DE TRABALHO FORMAL: UMA ANÁLISE DE DADOS NO ESTADO DO CEARÁ

EduARdo RÉGIS GirÃo de CASTRO PINTO ANA VIRGÍNIA MOREIRA GOMES

estimada em espaço, profundidade, intensidade etc). ${ }^{28} \mathrm{~A}$ característica mais marcante dessa técnica é a realização de observações de forma continuada, justamente para verificar se os eventos são dependentes ou consequentes.

Muito embora o período de coleta dos dados seja relativamente curto (novembro de 2017 até novembro de 2018), trata-se de um recorte epistemológico necessário à obtenção de respostas para o tema e que tornaria inútil ou desnecessária a reunião de dados em uma periodização maior, uma vez que o problema observado encontra aplicação justamente nesse período, que corresponde à introdução do contrato intermitente pela Reforma Trabalhista. A base de informações foi construída a partir de informações secundárias disponibilizadas pelo CAGED, Portal do Ministério do Trabalho e do Emprego e Relatórios de Relação Anual de Informações Sociais - RAIS e Pesquisa Nacional por Amostra de Domicílios Contínua PNAD/ IBGE, com a devida indicação dos meios de coleta para facilitar a replicabilidade.

A escolha pelas referidas instituições se justifica pela metodologia de coleta dos dados, acessibilidade dos metadados e atualidade das informações. O CAGED foi instituído pelo Ministério do Trabalho e Emprego a partir da publicação da Lei $n^{\circ} 4.923 / 65$, para identificar e registrar as admissões e demissões de empregados sob o regime da CLT de forma permanente, e cujas variáveis de coleta somam as admissões, desligamentos e estoques que possibilitam o cálculo do índice de emprego e a flutuação de emprego, identificando ainda os desagregados em nível geográfico e setorial.

Cumpre destacar que a escolha pela utilização de dados secundários se justifica porque permite que novos testes de hipóteses possam ser utilizados para replicar e verificar teorias, além de admitirem múltiplas possibilidades de análises e admitirem comparações através do tempo. ${ }^{29}$ Para que a pesquisa científica possa ser considerada como tal, deve ser comparada por fundamentos teóricos consistentes, que devem ser avaliados e escolhidos por cada pesquisador. Trata-se de um padrão que estabelece um nível alto para a pesquisa (mas não uma meta impossível), em que a recomendação principal se concentra no bom uso das informações coletadas e inferências válidas, razão pela qual se justifica o cuidado com a coleta dos dados.

No que se refere ao tipo de coleta, opta-se, aqui, pela pesquisa por amostras, em que uma parte da população é considerada justamente pela impossibilidade da análise integral, o que faz com que a resposta dada pela amostra tente significar um padrão representativo do

\footnotetext{
${ }^{28}$ SHUMWAY, Robert H.; STOFFER, David S. Time series analysis and its applications with R examples. London: Springer International Publishing AG, 2017.

${ }^{29}$ RATHKE, Julia. Achieving comparability of secondary data. In: GSCHWEND, Thomas; SCHIMMELFENNIG, Frank. Research design: how to practice what they preach. England: British Library, 2011, p. 103-126.
} 
ISSN 1981-3694

(DOI): $10.5902 / 1981369436822$

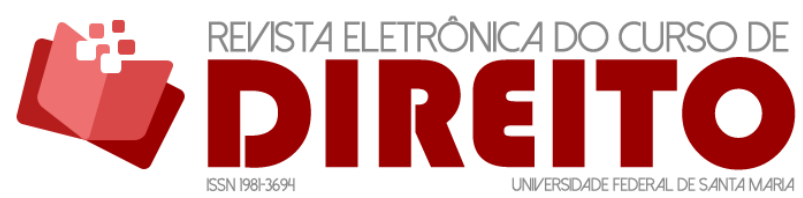

OS EFEITOS DO CONTRATO INTERMITENTE NA CRIAÇÃO DE NOVOS POSTOS DE TRABALHO FORMAL: UMA ANÁLISE DE DADOS NO ESTADO DO CEARÁ

EduARdo RÉGIS GirÃo de CASTRO PINTO ANA VIRGÍNIA MOREIRA GOMES

todo. Para tal, é necessário selecionar uma amostra com base na escolha ideal de uma unidade de análise representativa. No contexto da presente pesquisa, justifica-se a seleção do Estado do Ceará como recorte espacial para a coleta de informações pelo ineditismo e possível contribuição para a teoria sobre o tema, além da acessibilidade quanto aos dados.

Para o recorte temporal, entende-se pela utilização de um marco temporal sucinto, porém representativo para a análise do fenômeno. Como marco inicial, tem-se o ano de 2017, a partir do mês de novembro, por coincidir com o período de introdução da Reforma Trabalhista e consequente adoção do contrato intermitente. Como marco final, tem-se o ano de 2018, como atualização máxima da coleta e tratamento das informações. A periodização parece ser suficiente para responder ao problema de pesquisa, inferir resultados fiáveis e fornecer explicações de médio alcance.

Para tentar responder ao problema de pesquisa e verificar se é possível argumentar que houve uma evolução do saldo do emprego formal no setor de serviços a partir da criação do contrato de trabalho intermitente pela Lei n 13.467/2017 - Reforma Trabalhista, será realizada uma comparação entre os indicadores do emprego formal em escala nacional e, em seguida, em nível local, observando informações desde 2016 (que, muito embora não perfaçam o recorte temporal indicado, são úteis para uma análise retrospectiva do objeto).

Como objetivo geral, verifica-se a necessidade de atestar se a Reforma Trabalhista gerou algum efeito na criação de novos postos de trabalho formal no setor de serviços no Estado do Ceará, o que deve ser analisado sob o ponto de vista da utilização do contrato atípico sem a interferência de covariáveis, justamente para aferir se a Reforma é útil como estratégia de regulação do mercado de trabalho.

Como hipóteses, destacam-se as seguintes proposições: (H1) A Reforma Trabalhista gerou efeitos sobre a variação quantitativa de postos de trabalho formal no setor de serviços no Estado do Ceará; (H2) Todos os setores podem ter sofrido efeitos negativos quanto ao número de postos de trabalho sob o contrato típico a partir da adoção do contrato intermitente.

Para testar a hipótese $1(\mathrm{H} 1)$, será realizada comparação entre o número de postos de trabalho antes e depois da reforma, pontualmente para o setor de serviços. Se tiver havido aumento no número de postos de trabalho sem que tenha ocorrido qualquer outro evento relevante, é possível considerar como uma possibilidade a interferência da introdução da Reforma. Para testar a hipótese $2(\mathrm{H} 2)$, é preciso comparar a variância quanto ao número de postos de trabalho em todos os setores, especialmente no que diz respeito ao período anterior e posterior à adoção da Reforma. 
Quanto ao setor pesquisado como foco da análise, entende-se pela seleção do setor de serviços, por ser o ramo de maior progressão no que se refere ao número de empregos formais no país no período recente de 2016 a 2017, conforme se observa na Figura 3:

Figura 3: Número de empregos formais por setor de atividade (2016 a 2017)

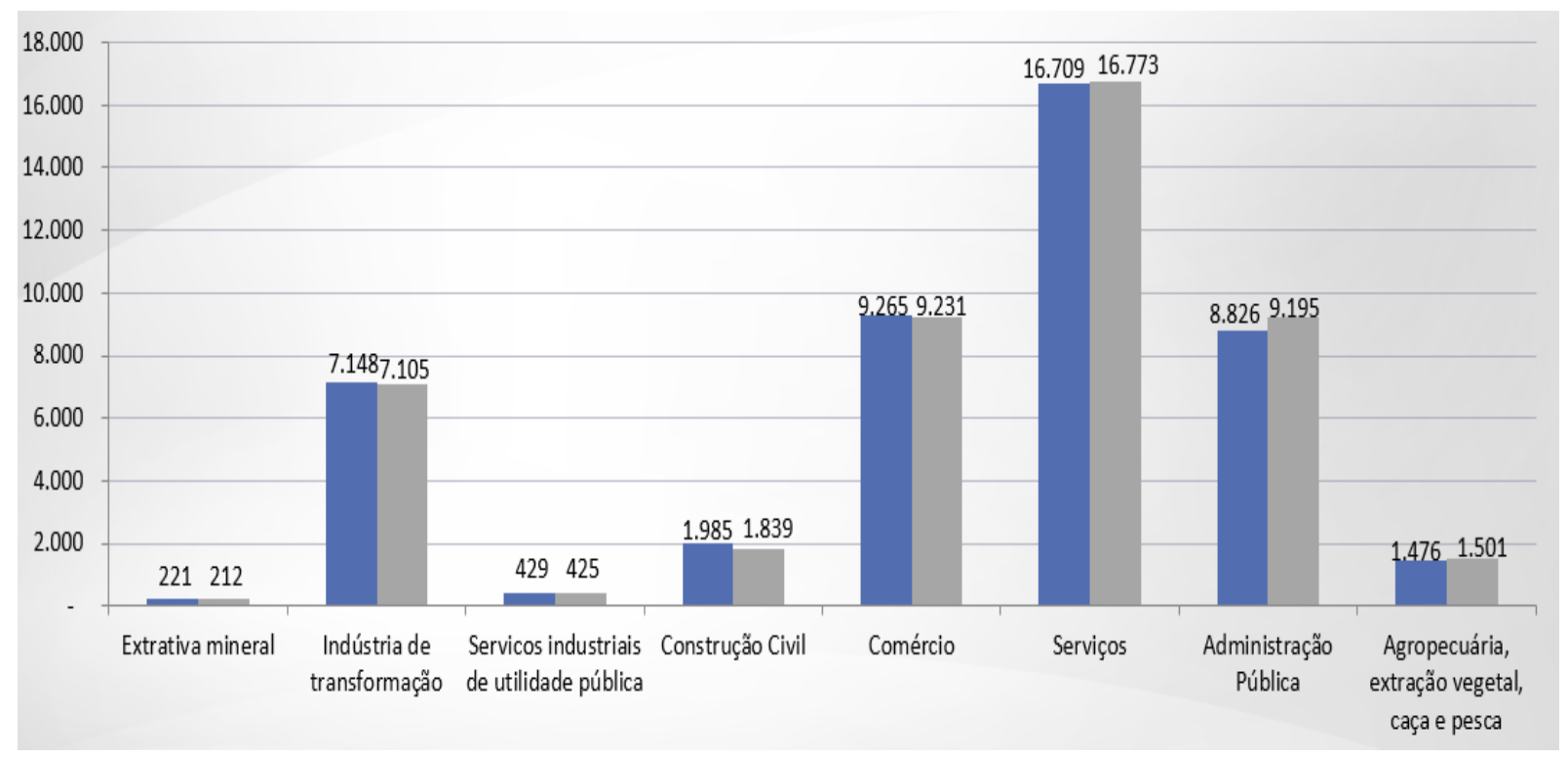

Fonte: Relatório Relação Anual de Informações Sociais - RAIS. Ministério do Trabalho e Emprego (2017, online). ${ }^{30}$

É possível verificar que o setor de serviços tem apresentado maior crescimento em termos absolutos comparativamente aos demais setores registrados pelo Ministério do Trabalho e Emprego no que diz respeito ao mercado formal, superando atividades como os serviços relacionados à Administração Pública (19,87\% do total), Comércio e Indústria de Transformação (15,35\% do total), evidenciando ser uma atividade de considerável relevância para a pesquisa, respondendo por $36,24 \%$ do total de setores registrados. ${ }^{31}$

\footnotetext{
${ }^{30}$ BRASIL. Ministério do Trabalho e Emprego. Relatório Relação Anual de Informações Sociais - RAIS. Disponível em: http://pdet.mte.gov.br/index.php/rais. Acesso em: 20 out. 2018

${ }^{31}$ BRASIL. Ministério do Trabalho e Emprego. Relatório Relação Anual de Informações Sociais - RAIS. Disponível em: http://pdet.mte.gov.br/index.php/rais. Acesso em: 20 out. 2018.
} 
Figura 4: Evolução do número de empregos formais (1985 a 2017)

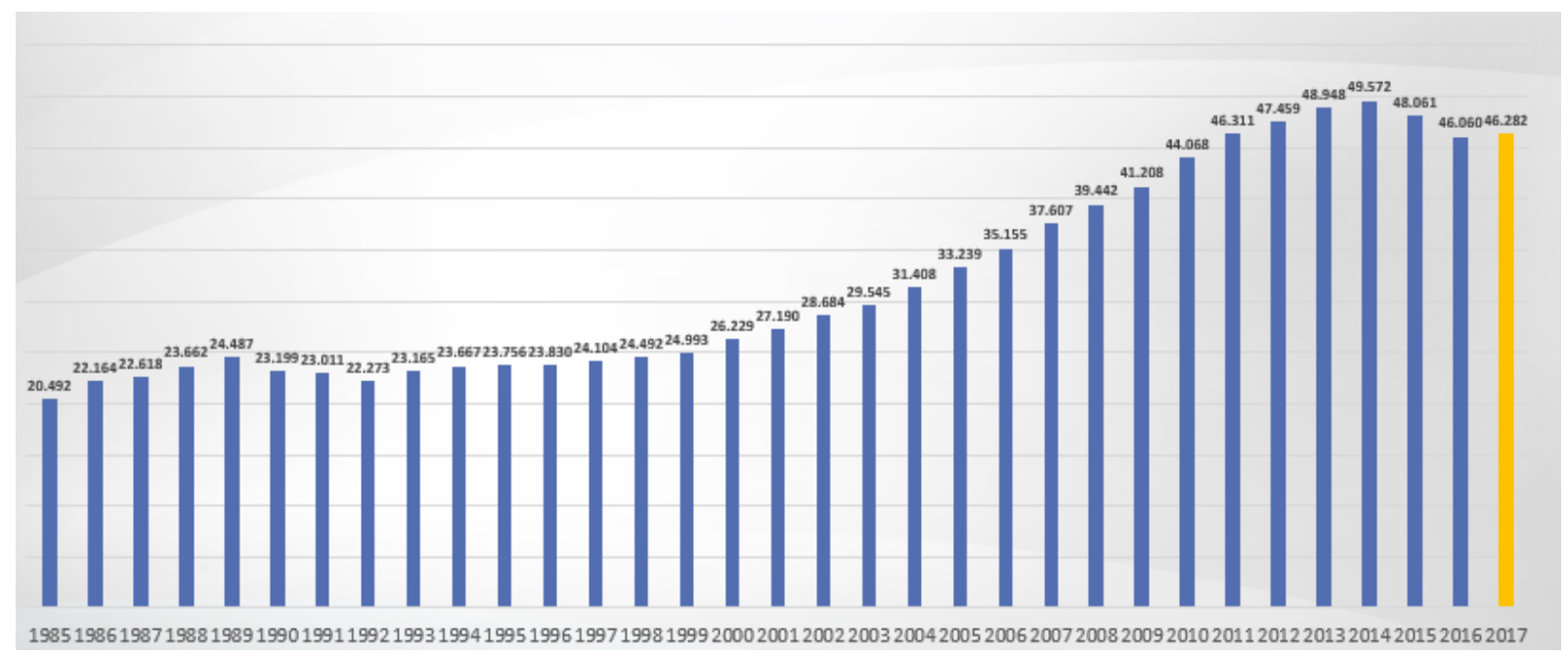

Fonte: Relatório Relação Anual de Informações Sociais - RAIS. Ministério do Trabalho e Emprego (2017, online). ${ }^{32}$

A partir da Figura 4, é possível perceber que houve relativa estabilidade quanto ao número de empregos formais registrados pelo Ministério do Trabalho e Emprego entre 2015 e 2017, mas uma sensível queda se considerados os últimos sete anos do período total analisado, em um panorama nacional, em que houve aumento no índice de informalidade e queda da formalidade evidenciado pela PNAD/IBGE.

O relatório evidencia um panorama geral, sem justificar as covariáveis e limitando a análise ao recorte, que considera apenas os números absolutos da progressão do emprego formal. Não há indicadores precisos nessa análise sobre o tipo de contrato a partir de 2017, se típicos ou atípicos. A oferta de empregos formais na Região Nordeste do Brasil tem oscilado entre as unidades federativas consultadas, o que foi coletado justamente para responder ao objetivo da pesquisa que consiste, complementarmente, em verificar como unidade de análise o Estado do Ceará.

Na Figura 5, abaixo, verifica-se uma variância positiva de 1,50 \% quanto ao número de empregos formais no Ceará, entre 2016 e 2017, representando um aumento absoluto de 21.583

32 BRASIL. Ministério do Trabalho e Emprego. Relatório Relação Anual de Informações Sociais - RAIS. Disponível em: http://pdet.mte.gov.br/index.php/rais. Acesso em: 20 out. 2018. 
ISSN 1981-3694

(DOI): $10.5902 / 1981369436822$

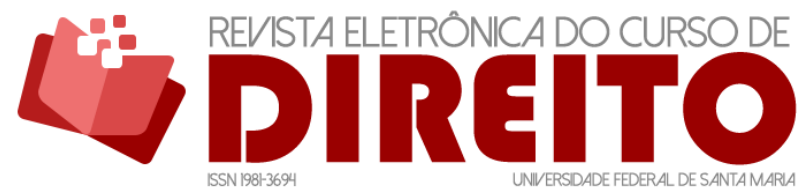

OS EFEITOS DO CONTRATO INTERMITENTE NA CRIACÃO DE NOVOS POSTOS DE TRABALHO FORMAL: UMA ANÁLISE DE DADOS NO ESTADO DO CEARÁ

EduARdo RÉGIS GirÃo de CASTRO PINTO ANA VIRGÍNIA MOREIRA GOMES

vagas de trabalho, superando Estados como Alagoas e Pernambuco, que tiveram variância negativa e posicionando-se como o segundo Estado do Nordeste com os indicadores mais relevantes quanto ao aumento de postos de trabalho.

Figura 5: Empregos formais por unidade da federação - Nordeste (2017)

\begin{tabular}{|c|c|c|c|c|}
\hline $\begin{array}{l}\text { Unidade } \\
\text { Federativa }\end{array}$ & 2016 & 2017 & $\begin{array}{l}\text { Variação } \\
\text { absoluta }\end{array}$ & $\begin{array}{l}\text { Variação relativa } \\
(\%)\end{array}$ \\
\hline Nordeste & 8.436 .203 & 8.543 .651 & 107.448 & 1,27 \\
\hline Alagoas & 490.272 & 486.763 & 3.509 & $-0,72$ \\
\hline Bahia & 2.171 .345 & 2.223 .775 & 52.430 & 2,41 \\
\hline Ceará & 1.443 .365 & 1.464 .948 & 21.583 & 1,50 \\
\hline Maranhão & 700.200 & 713.051 & 12.851 & 1,84 \\
\hline Paraíba & 634.632 & 638.270 & 3.638 & 0,57 \\
\hline Pernambuco & 1.585 .654 & 1.584 .780 & 874 & $-0,06$ \\
\hline Piauí & 441.693 & 453.229 & 11.536 & 2,61 \\
\hline Rio Grande do Norte & 585.969 & 588.373 & 2.404 & 0,41 \\
\hline Sergipe & 383.073 & 390.462 & 7.389 & 1,93 \\
\hline
\end{tabular}

Fonte: Relatório Relação Anual de Informações Sociais - RAIS. Ministério do Trabalho e Emprego (2017, online)..$^{33}$

Todavia, a mera observância quanto ao aumento no número de vagas não implica, necessariamente, em considerar que o mercado formal permanece invariavelmente, sob a regulação do mesmo tipo de contrato. Para verificar se a Reforma Trabalhista surtiu algum efeito nesse quantitativo, é preciso compreender que a adoção do contrato intermitente pode ter influído na migração do trabalhador do contrato de trabalho típico para as vagas regidas pelo contrato intermitente.

Assim, para verificar a realidade da adoção do contrato intermitente, colaciona-se o conteúdo da Figura 6, que identifica o tipo de setor mais afetado pela adoção do contrato intermitente de trabalho.

33 BRASIL. Ministério do Trabalho e Emprego. Relatório Relação Anual de Informações Sociais - RAIS. Disponível em: http://pdet.mte.gov.br/index.php/rais. Acesso em: 20 out. 2018. 
Figura 6: Empregos formais por setor e ocupação por contrato intermitente (2017).
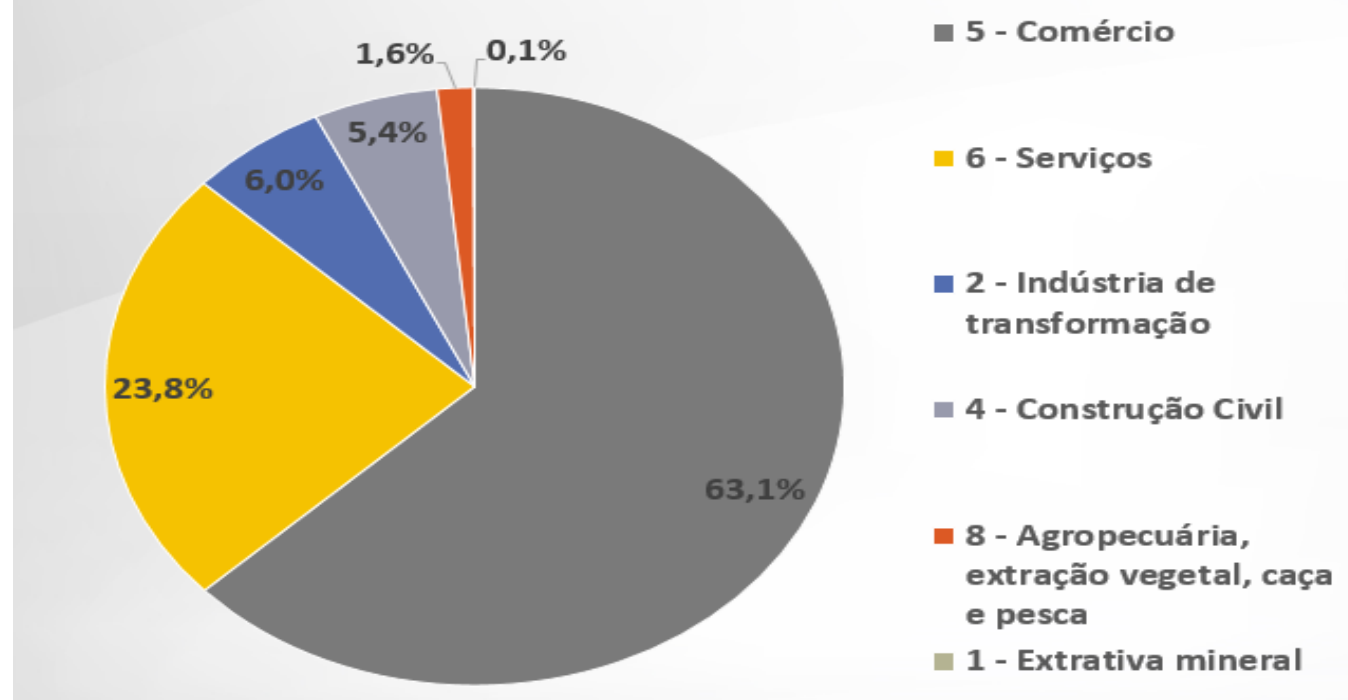

Fonte: Relatório Relação Anual de Informações Sociais - RAIS. Ministério do Trabalho e Emprego (2017, online). ${ }^{34}$

A partir da interpretação da Figura 6 comparativamente aos dados demonstrados pela Figura 1, é possível perceber que o setor de serviços sofreu considerável queda, especialmente se comparado ao setor de Construção Civil, cuja atividade evoluiu quanto à variação quantitativa. Ou seja; o setor de serviços sofreu variância negativa (de 36,24\% para 23,8\%) a partir de 2017, o que pode ser relacionado, como condição necessária, mas não suficiente, à adoção do contrato de trabalho intermitente (uma vez que pode ter havido a mera migração de profissionais de um setor para outro do mercado formal).

Assim, de acordo com os dados coletados e a partir de uma análise cross-sectional, considerando-se variáveis como unidade de análise, periodização e setor, é possível falar em variação quantitativa do número de postos de emprego a partir da criação do contrato de trabalho intermitente pela Reforma Trabalhista de 2017. Mas, se a variação é negativa para o setor de serviços, e positiva para outros setores; é possível inferir que o número de postos tenha se mantido e que a alteração pontual tenha ocorrido no tipo de contrato.

${ }^{34}$ BRASIL. Ministério do Trabalho e Emprego. Relatório Relação Anual de Informações Sociais - RAIS. Disponível em: http://pdet.mte.gov.br/index.php/rais. Acesso em: 20 out. 2018. 
ISSN 1981-3694

(DOI): $10.5902 / 1981369436822$

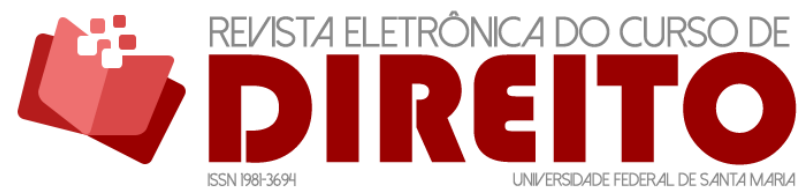

OS EFEITOS DO CONTRATO INTERMITENTE NA CRIAÇÃO DE NOVOS POSTOS DE TRABALHO FORMAL: UMA ANÁLISE DE DADOS NO ESTADO DO CEARÁ

EduARdo RÉGIS GirÃo de CASTRO PINTO ANA VIRGÍNIA MOREIRA GOMES

Quanto à variação da ocupação de postos de trabalho no mercado formal, sob a análise específica do recorte espacial da presente pesquisa (Estado do Ceará), importa considerar a diferença no quantitativo sob uma variância aparentemente positiva, como é possível assinalar pela leitura da Figura 7;

Figura 7: Número de postos de trabalho formal no Estado do Ceará (2016 a 2017).

\subsection{0 .000 \\ 1.465 .000 \\ 1.460 .000 \\ 1.455 .000 \\ 1.450 .000 \\ 1.445 .000 \\ 1.440 .000 \\ 1.435 .000 \\ 1.430 .000}

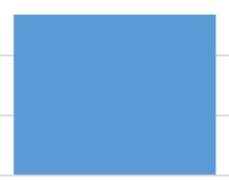

2016

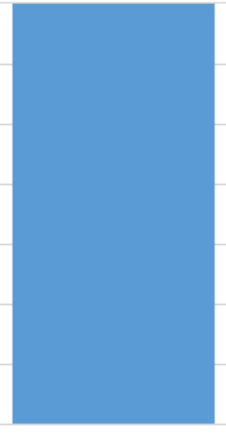

2017

Fonte: Elaboração própria com base no Relação Anual de Informações Sociais (Rais), do Ministério do Trabalho e Emprego (MTE), 2018..$^{35}$

Em números absolutos, no ano de 2017, foram contabilizadas 21.583 novas vagas de trabalho formal, com destaque para a geração de vagas na área de Administração Pública, com saldo de 34.641 postos, seguido pelos Serviços Industriais de Utilidade Pública, com um saldo de 509 vagas. Entretanto, de acordo com o mesmo estudo, houve redução de vagas nos seguintes setores: Indústria de Transformação, com variância negativa de 6.488 vagas; Construção Civil, com redução de 5.249 postos de trabalho; Setor de Comércio, com um desfalque de 1.855 postos e área Extrativa Mineral, com menos 298 vagas, de acordo com dados revelados pela Relação Anual de Informações Sociais (Rais), do Ministério do Trabalho e Emprego (MTE), de novembro de 2018.

Cumpre assinalar que essa redução pode indicar uma migração entre modalidades de contrato. Nos demais setores do mercado de trabalho formal no âmbito do Estado do Ceará, importa considerar:

35 BRASIL. Ministério do Trabalho e Emprego. Relatório Relação Anual de Informações Sociais - RAIS. Disponível em: http://pdet.mte.gov.br/index.php/rais. Acesso em: 20 out. 2018. 
Tabela 1: Variância numérica dos empregos formais no Estado do Ceará por setor (2016 a 2017).

\begin{tabular}{|l|l|l|l|l|l|}
\hline $\begin{array}{l}\text { Setor da atividade } \\
\text { econômica }\end{array}$ & 2016 & 2017 & $\begin{array}{l}\text { Variação } \\
\text { absoluta }\end{array}$ & $\begin{array}{l}\text { Variação } \\
\text { relativa (\%) }\end{array}$ & $\begin{array}{l}\text { Variância } \\
\text { média } \\
(0 / 1)\end{array}$ \\
\hline Extrativa mineral & 2.999 & 2.701 & -298 & $-9,94$ & 1 \\
\hline Indústria da transformação & 23.250 & 22.013 & -1.235 & $-2,79$ & 1 \\
\hline $\begin{array}{l}\text { Serviços industriais de } \\
\text { utilidade pública }\end{array}$ & 8.556 & 9.062 & 506 & 5,91 & 0 \\
\hline Construção civil & 20.018 & 25.267 & 5.249 & 8,53 & 0 \\
\hline Comércio & 260.979 & 259.124 & -1.855 & $-0,71$ & 1 \\
\hline Serviços & 483.741 & 484.052 & 311 & 0,06 & 0 \\
\hline Administração pública & 369.758 & 404.399 & 34.641 & 9,37 & 0 \\
\hline Agropecuária & 23.315 & 23.330 & 15 & 0,06 & 1 \\
\hline Total & 1.443 .365 & 1.464 .948 & 21.583 & 1,5 & - \\
\hline
\end{tabular}

Fonte: Elaboração própria com base no Relação Anual de Informações Sociais (Rais), do Ministério do Trabalho e Emprego (MTE), 2018. ${ }^{36}$

A variância média foi destacada em caracteres binários; considerando ' 0 ' para o aumento no número de postos de trabalho por setor, e '1' para a redução no número de postos de trabalho por setor. É possível perceber que o aumento do número de postos de trabalho ocorreu nos setores de Serviços Industriais de Utilidade Pública, Construção Civil, Serviços e Administração Pública.

O número de postos de trabalho diminuiu nos setores de Indústria da transformação, área extrativa mineral, comércio e agropecuária. Porém, embora os valores apresentem variância considerável, não é possível identificar que a alteração ocorreu necessariamente em

${ }^{36}$ BRASIL. Ministério do Trabalho e Emprego. Relatório Relação Anual de Informações Sociais - RAIS. Disponível em: http://pdet.mte.gov.br/index.php/rais. Acesso em: 20 out. 2018. 
ISSN 1981-3694

(DOI): $10.5902 / 1981369436822$

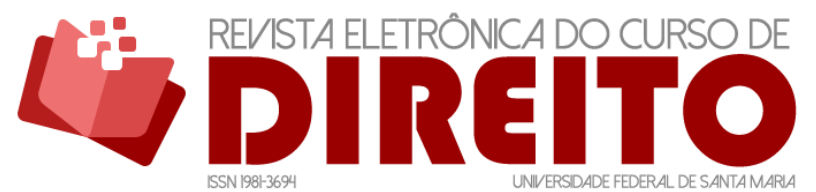

OS EFEITOS DO CONTRATO INTERMITENTE NA CRIAÇÃO DE NOVOS POSTOS DE TRABALHO FORMAL: UMA ANÁLISE DE DADOS NO ESTADO DO CEARÁ

EduARdo RÉGIS GIRÃo de CASTRO PINTO ANA VIRGÍNIA MOREIRA GOMES

razão da introdução dos contratos intermitentes, uma vez que é provável a migração entre setores dada a alteração de modalidades de contrato.

A Relação Anual de Informações Sociais (Rais), do Ministério do Trabalho e Emprego (MTE), instrumento dos mais completos para a inclusão, registro e acompanhamento nacional de informações referentes ao comportamento das oscilações de vagas e oferta dos postos de trabalho formal no Brasil, ainda não possui dados compilados sobre a variância de postos de trabalho em 2018, o que evidencia uma limitação metodológica para a pesquisa.

Para verificar se a estratégia de regulação do mercado de trabalho é eficaz ou não, também é preciso identificar se as previsões de curto e médio alcance se realizaram. De acordo com as projeções feitas pela Frente Parlamentar Mista em Defesa do Comércio, Serviços e Empreendedorismo, utilizando como base os indicadores da economia norte-americana, estimase que o contrato intermitente proposto pela Reforma Trabalhista tenderia a gerar "catorze milhões de postos de trabalho formais no espaço de 10 anos" (Parecer do Relator apresentado na Comissão Especial do Projeto de Lei $n^{\circ} 6.787 / 2016$, p. 50).

Ao comparar com os dados mais recentes da Pesquisa Nacional por Amostra de Domicílios Contínua PNAD/ IBGE, que registra e divulga informações contínuas sobre a inserção da população brasileira no mercado de trabalho, associando essa inserção a caracteres demográficos e socioeconômicos, é possível destacar que a taxa de desemprego tem sofrido variações relevantes.

Figura 8: Variação Mensal da Taxa de Desemprego (janeiro de 2012 a outubro de 2018).

\begin{tabular}{|r|r|r|r|r|r|r|r|r|r|r|r|r|r|}
\hline & Jan & Fev & Mar & Abr & Mai & Jun & Jul & Ago & Set & Out & Nov & Dez \\
\hline 2012 & - & - & 7,90 & 7,80 & 7,50 & 7,50 & 7,40 & 7,30 & 7,10 & 6,90 & 6,80 & 6,90 \\
\hline 2013 & 7,20 & 7,70 & 8,00 & 7,80 & 7,60 & 7,40 & 7,30 & 7,10 & 6,90 & 6,70 & 6,50 & 6,20 \\
\hline 2014 & 6,40 & 6,80 & 7,20 & 7,10 & 7,00 & 6,80 & 6,90 & 6,90 & 6,80 & 6,60 & 6,50 & 6,50 \\
\hline 2015 & 6,80 & 7,40 & 7,90 & 8,00 & 8,10 & 8,30 & 8,60 & 8,70 & 8,90 & 9,00 & 9,00 & 9,00 \\
\hline 2016 & 9,50 & 10,20 & 10,90 & 11,20 & 11,20 & 11,30 & 11,60 & 11,80 & 11,80 & 11,80 & 11,90 & 12,00 \\
\hline 2017 & 12,60 & 13,20 & 13,70 & 13,60 & 13,30 & 13,00 & 12,80 & 12,60 & 12,40 & 12,20 & 12,00 & 11,80 \\
\hline 2018 & 12,20 & 12,60 & 13,10 & 12,90 & 12,70 & 12,40 & 12,30 & 12,10 & 11,90 & 11,70 & - & - \\
\hline
\end{tabular}

Fonte: PNAD - Contínua (2018, online). ${ }^{37}$

\footnotetext{
37 INSTITUTO BRASILEIRO DE GEOGRAFIA E ESTATÍSTICA. Pesquisa Nacional por Amostra de Domicílios Contínua - PNAD Contínua. Disponível em: https://www.ibge.gov.br/estatisticas-
} 
Para responder aos objetivos do trabalho, especialmente dentro do período selecionado para a análise, é preciso identificar a variação de desemprego entre novembro de 2017 até outubro de 2018, considerando os marcos inicial e final para o estudo:

Figura 9: Variação percentual de desemprego no mercado formal (novembro de 2017 a outubro de 2018).

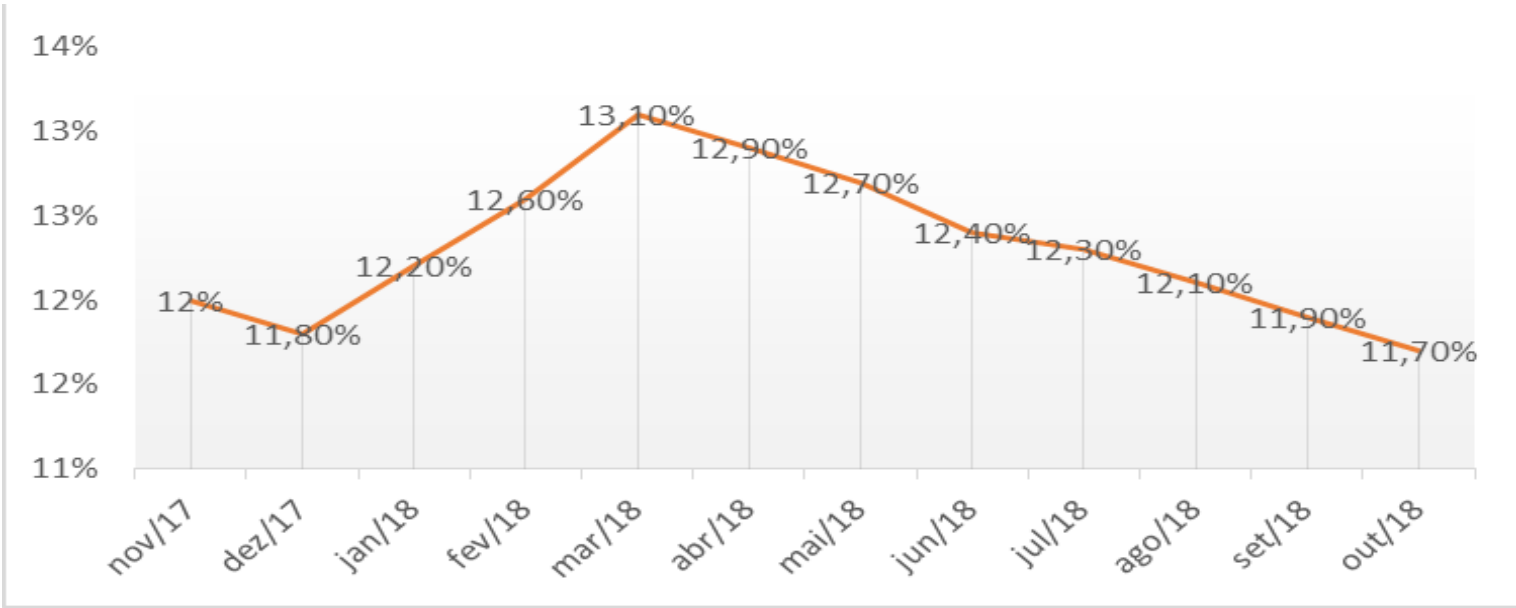

Fonte: Elaboração própria com base nos dados fornecidos pelo PNAD - Contínua (2018, online). ${ }^{38}$

A partir da figura acima, é possível constatar que o Parecer do Relator apresentado na Comissão Especial do Projeto de Lei n 6787/2016 não corresponde à realidade do desemprego no Brasil dentro do período observado, uma vez que, para atingir "catorze milhões de postos de trabalho formais no espaço de 10 anos" seria o equivalente a sugerir a abertura de mais de 116 mil postos de trabalho por mês, igualmente em todas as unidades federativas, o que se incompatibiliza com as perspectivas de crescimento.

De acordo com dados do CAGED (2018), é possível perceber que a geração de postos de trabalho não significa, necessariamente, a progressão do emprego ou a redução de crises da oferta de cargos, uma vez que há migração de postos e diferenças quanto ao desempenho setorial, conforme o que segue:

novoportal/sociais/educacao/9171-pesquisa-nacional-por-amostra-de-domicilios-continuamensal.html?=\&t=o-que-e. Acesso em: 30 nov. 2018.

38 INSTITUTO BRASILEIRO DE GEOGRAFIA E ESTATÍ́sTICA. Pesquisa Nacional por Amostra de Domicílios Contínua - PNAD Contínua. Disponível em: https://www.ibge.gov.br/estatisticasnovoportal/sociais/educacao/9171-pesquisa-nacional-por-amostra-de-domicilios-continuamensal.html?=\&t=o-que-e. Acesso em: 30 nov. 2018. 
Tabela 2: Saldo de novos postos de trabalho no Brasil (janeiro de 2018 a dezembro de 2018)

\begin{tabular}{|l|l|l|l|l|}
\hline Modalidade & $\begin{array}{l}\text { Número de } \\
\text { Admissões }\end{array}$ & $\begin{array}{l}\text { Número } \\
\text { de } \\
\text { Demissões }\end{array}$ & Saldo & $\begin{array}{l}\text { Setores mais } \\
\text { beneficiados }\end{array}$ \\
\hline Mercado Formal & 1.234 .591 & 1.097 .255 & 137.336 & Serviços \\
\hline Trabalho Intermitente & 6.072 & 1.791 & 4.281 & $\begin{array}{l}\text { Serviços e Construção } \\
\text { Civil }\end{array}$ \\
\hline $\begin{array}{l}\text { Trabalho em Regime } \\
\text { Parcial }\end{array}$ & 5.451 & 3.477 & 1.974 & Serviços \\
\hline
\end{tabular}

Fonte: Cadastro Geral de Empregados e Desempregados - CAGED, 2018. ${ }^{39}$

Figura 10: Saldo de Empregos formais no Brasil (novembro de 2017 a novembro de 2018).

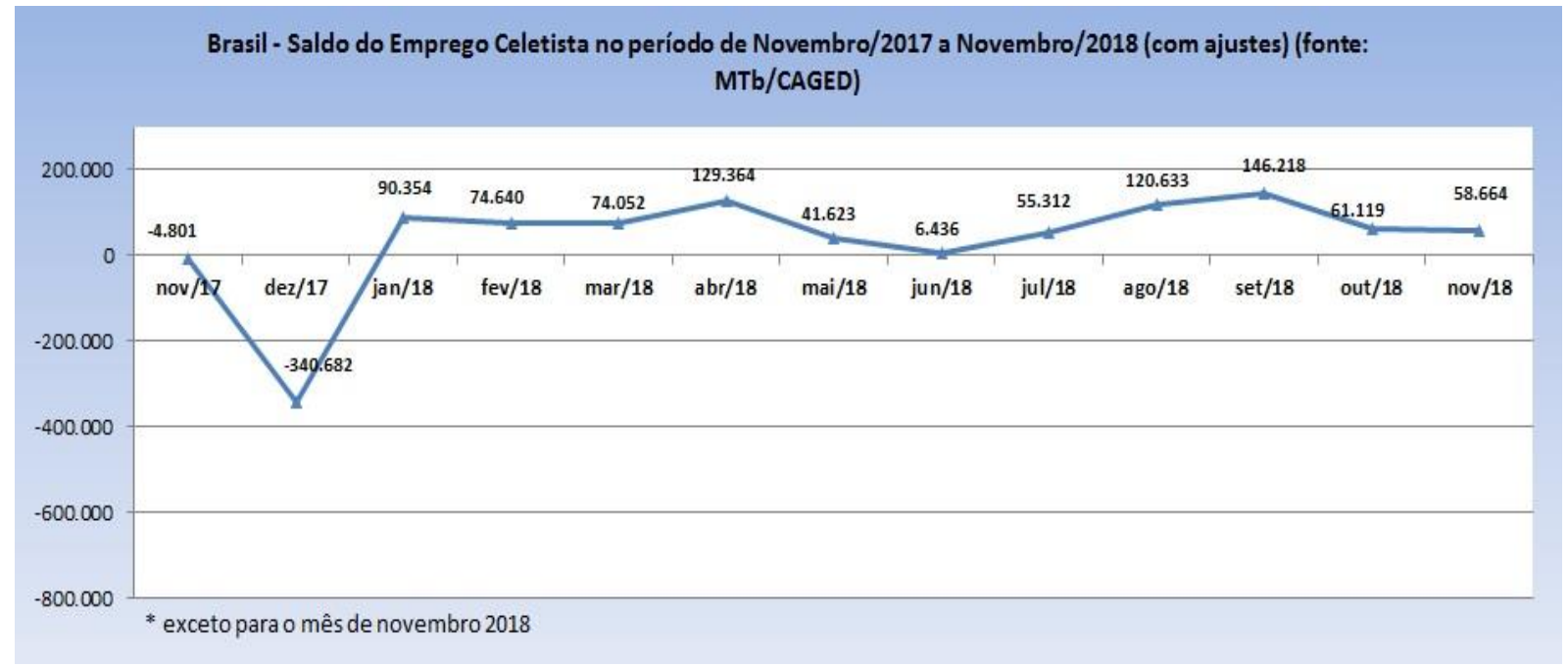

Fonte: Cadastro Geral de Empregados e Desempregados - CAGED, 2018. ${ }^{40}$

Em uma perspectiva nacional, o CAGED registrou o aumento no número de postos de trabalho, mas um equivalente aumento nos indicadores de demissão / desligamento, evidenciando uma variância pouco significativa no que se refere ao saldo de novos postos. É

39 BRASIL. Ministério do Trabalho. Cadastro Geral de Empregados e Desempregados - CAGED. Disponível em: http://trabalho.gov.br/trabalhador-caged. Acesso em: 29 nov. 2018.

40 BRASIL. Ministério do Trabalho. Cadastro Geral de Empregados e Desempregados - CAGED. Disponível em: http://trabalho.gov.br/trabalhador-caged. Acesso em: 29 nov. 2018. 
ISSN 1981-3694

(DOI): $10.5902 / 1981369436822$

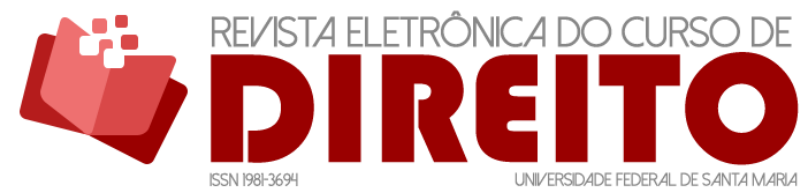

OS EFEITOS DO CONTRATO INTERMITENTE NA CRIAÇÃO DE NOVOS POSTOS DE TRABALHO FORMAL: UMA ANÁLISE DE DADOS NO ESTADO DO CEARÁ

EduARdo RÉGIS GIRÃo de CASTRO PINTO ANA VIRGÍNIA MOREIRA GOMES

possível perceber, pelo demonstrativo exposto na Figura 10, que o saldo de empregos regidos pela CLT não teve progressão significativa nos meses analisados, o que não se compatibiliza com a previsão do Parecer do Relator apresentado na Comissão Especial do Projeto de Lei $n^{\circ}$ $6787 / 2016$.

Se no Estado do Ceará, durante todo ano de 2017 foram ofertadas 21.583 vagas de trabalho em todos os setores, o que já representa um número bastante significativo se comparado aos demais Estados do Nordeste brasileiro (vide Figura 3), talvez pareça uma projeção excessiva considerar que o número de postos de trabalho crescerá tão exponencialmente em razão da adoção do contrato intermitente.

Ademais, considerando que a taxa de desemprego da população brasileira ativa progrediu de $11,8 \%$ em dezembro de 2017 (equivalente a 12.311 milhões de pessoas) para 11,7\% em outubro de 2018 (12.351 milhões de pessoas); verifica-se uma taxa de crescimento de apenas 0,32\%, comparativamente ao ano anterior - o que aduz à percepção de sensível redução quanto ao nível de desemprego (que beira à estabilidade) e não de progressão ou variância positiva, apesar de todas as iniciativas e estratégias propostas.

Ainda, é necessário considerar os riscos a médio e longo prazo, quando se fala da adoção de uma modalidade de contrato que possui menor segurança e confere menor estabilidade ao trabalhador.

\section{CONCLUSÃO}

Como resposta ao problema de pesquisa e a partir dos dados analisados no período de estudo, não é possível falar em uma evolução do saldo do emprego formal no setor de serviços a partir da criação do contrato de trabalho intermitente pela Lei $n^{\circ} 13.467 / 2017$ - Reforma Trabalhista. Além de verificar que a progressão ou não dos indicadores de desemprego pode se relacionar com covariáveis múltiplas (como peculiaridades de cada unidade federativa, tipo de trabalho desenvolvido, modalidade de contrato etc.), identifica-se também que a adoção do contrato intermitente não resultou em um aumento significativo do número de postos de trabalho formal.

Assinale-se que a modalidade dos contratos utilizados também pode influir nos resultados verificados sob o enfoque qualitativo, na medida em que o contrato informal pode caracterizar admissão irregular e que os contratos por tempo determinado e trabalho eventual estabelecem a 
ISSN 1981-3694

(DOI): $10.5902 / 1981369436822$

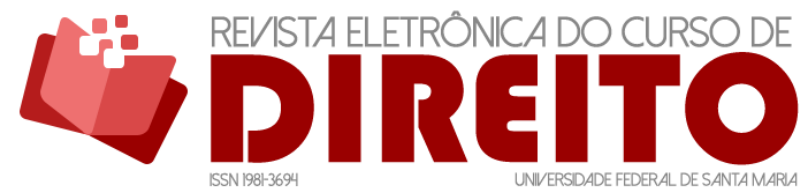

OS EFEITOS DO CONTRATO INTERMITENTE NA CRIAÇ̃̃O DE NOVOS POSTOS DE TRABALHO FORMAL: UMA ANÁLISE DE DADOS NO ESTADO DO CEARÁ

EduARdo RÉGIS GIRÃo de CASTRO PINTO ANA VIRGÍNIA MOREIRA GOMES

finalização do exercício da função em período pré-determinado, o que poderia influir nos indicadores da informalidade objeto de estudo.

Quanto às inferências desenvolvidas é necessário assinalar que a hipótese 1, "a reforma trabalhista gerou efeitos sobre a variação quantitativa de postos de trabalho formal no setor de serviços no Estado do Ceará" foi refutada, uma vez que não se verificou aumento relativo na variância do número de postos de trabalho em decorrência da alteração na modalidade de contrato. A variância gerada foi não significativa, comparativamente à perspectiva nacional.

A hipótese 2 "todos os setores podem sofrer efeitos negativos quanto ao número de postos de trabalho sob o contrato típico a partir da adoção do contrato intermitente" também não foi atestada, na medida em que o aumento do número de postos de trabalho, no Estado do Ceará, ocorreu nos setores de Serviços Industriais de Utilidade Pública, Construção Civil, Serviços e Administração Pública, mas diminuiu nos setores de Indústria da transformação, área extrativa mineral, comércio e agropecuária.

Além disso, embora os valores apresentem variância considerável, não é possível identificar que a alteração ocorreu unicamente em razão da introdução dos contratos intermitentes, uma vez que pode ter havido migração entre setores dada a alteração de modalidades de contrato.

É possível concluir, ainda, que os resultados demonstrados pelos indicadores de desemprego evidenciam a falta de funcionalidade da proposta, visto não ter sido cumprida conforme projeção e estimações governamentais. A diferença percentual de desemprego não é significativa em comparação ao nível de insegurança que pode causar ao trabalhador, além das possíveis consequências sociais da adoção da Reforma, como o enfraquecimento dos sindicatos, perda de direitos, terceirização e redução na arrecadação do Governo.

Percebe-se que a Reforma Trabalhista, a partir dos dados analisados, não foi pensada estrategicamente ou com base em suporte empírico suficientemente robusto, uma vez que não produziu mudanças significativas.

É necessário que a regulação do trabalho seja pensada de forma estratégica, considerando respostas a partir dos princípios do direito do trabalho e a partir das correlações, limitações e peculiaridades de cada circunstância, ou propor regulações setoriais, alinhadas com determinados tipos de atividade laboral. $O$ ato de construir uma regulação inteligente demanda 
ISSN 1981-3694

(DOI): $10.5902 / 1981369436822$

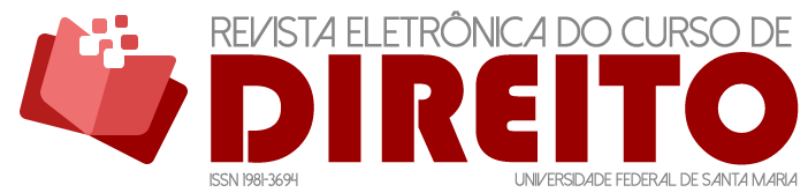

OS EFEITOS DO CONTRATO INTERMITENTE NA CRIAÇÃO DE NOVOS POSTOS DE TRABALHO FORMAL: UMA ANÁLISE DE DADOS NO ESTADO DO CEARÁ

EduARdo RÉGIS Girão de CASTRO PINTO ANA VIRGÍNIA MOREIRA GOMES

a busca pela qualidade, pela eficiência, e abrange formas flexíveis, imaginativas e inovadoras de controle social.

A Reforma Trabalhista, elaborada em um contexto político instável, reúne características que impactam na segurança do trabalhador brasileiro, sobretudo porque chegou a ocasionar mudanças importantes na legislação trabalhista, não necessariamente de maneira positiva em todos os aspectos.

\section{REFERÊNCIAS}

BARBOSA, Attila Magno e Silva; ORBEM, Juliani Veronezi. "Pejotização”: precarização das relações de trabalho, das relações sociais e das relações humanas. Revista Eletrônica do Curso de Direito da UFSM, Santa Maria, RS, dez. 2015, v. 10, n. 2, p. 839-859.

BRASIL. Exposição de Motivos da Medida Provisória n 808/2017. Disponível em: http: //www.planalto.gov.br/ccivil_03/_Ato2015-2018/2017/Exm/Exm-MP-808-17.pdf. Acesso em: 30 nov. 2018.

BRASIL. Ministério do Trabalho. Cadastro Geral de Empregados e Desempregados - CAGED. Disponível em: http://trabalho.gov.br/trabalhador-caged. Acesso em: 29 nov. 2018.

CASTRO, Rakel de; NASCIMENTO, José Shirley Pessoa do; SANTOS, Francisca Izabel A. dos. Reforma da previdência e trabalhista no Brasil: A democracia midiatizada no pós-impeachment de 2016. Estudos em Comunicação, 2018, n. 26, v. 2, p. 273-287.

COELHO, Gabriela. TST discutirá estabilidade de contrato de trabalho intermitente. Consultor Jurídico, 16 de setembro de 2018. Disponível em: https: / /www.conjur.com.br/2018-set-16/tstdiscutira-estabilidade-contrato-trabalho-intermitente. Acesso em: 23 nov. 2018.

CONSULTOR JURÍDICO. OIT classifica reforma trabalhista brasileira como violadora de direitos. Disponível em: https: //www.conjur.com.br/2018-mai-29/brasil-entra-lista-suja-oitcausa-reforma-trabalhista. Acesso em: 23 nov. 2018.

DEAKIN, Simon. The Capability Approach and the Economics of Labour Law. The Capability Approach to Labour Law, 2019, p. 147.

EVERA, Stephen Van. Guide to methods for students of political Science. Ithaca: Cornell University Press, 1997.

FLORES, Paulo. Como os contratos intermitentes devem afetar o mercado de trabalho. Disponível em: https://www.nexojornal.com.br/expresso/2017/11/28/Como-os-contratosintermitentes-devem-afetar-o-mercado-de-trabalho. Acesso em 30 nov. 2018.

FREITAS JR, Antônio Rodrigues de. 0 trabalho à procura de um direito: crise econômica, conflitos de classe e proteção social na Modernidade. Estudos avançados, 2014, v. 28, n. 81, p. 69-93, 
GOMES, Ana Virginia Moreira; PRADO, Mariana Mota. Flawed freedom of association in Brazil: how unions can become an obstacle to meaningful reforms in the labor law system. Comparative Labor Law and Policy Journal, 2010, v. 32, p. 843-861.

INSTITUTO BRASILEIRO DE GEOGRAFIA E ESTATÍ́STICA. Pesquisa Nacional por Amostra de Domicílios Contínua - PNAD Contínua. Disponível em: https://www.ibge.gov.br/estatisticasnovoportal/sociais/educacao/9171-pesquisa-nacional-por-amostra-de-domicilios-continuamensal.html?=\&t=o-que-e. Acesso em: 30 nov. 2018.

KAUFMAN, Bruce Evan, Labor Law and Employment Regulation: Neoclassical and Institutional Perspectives (July 2008). Andrew Young School of Policy Studies Research Paper No. 08-27.

KOLBEN, Kevin et al. Labour regulation, capabilities, and democracy. Labour regulation and development: Socio-legal perspectives, 2016, p. 60-81.

KOUMENTA, Maria; WILLIAMS, Mark. An anatomy of zero-hour contracts in the UK. Industrial Relations Journal, 50:1, 2018, p. 20-40.

LANGILLE, Brian. Imagining Post “Geneva Consensus" Labor Law for Post "Washington Consensus" Development. Comparative Labor Law and Policy Journal, 2009, v. 31, p. 523-531.

MONTEIRO, N Joana C. M.; ASSUNÇÃO, Juliano J. Contratos de Trabalho nas microempresas no Brasil. Pesquisa e Planejamento Econômico. v. 39, n. 1, abr. 2009, p. 01-24.

Parecer do Relator apresentado na Comissão Especial do Projeto de Lei $n^{\circ}$ 6.787/2016. Comissão Especial Destinada a Proferir Parecer ao Projeto de Lei $n^{\circ} 6.787 / 2016$. Relator: Deputado Rogério Marinho.

POPPER, Karl. The logic of scientific discovery. London, Routledge, 1995.

PINTO, Marcio Morena. La fundamentalidad de los derechos sociolaborales desde la perspectiva de la dignidad de la persona humana. Revista Eletrônica do Curso de Direito da UFSM, Santa Maria, RS, ago. 2016, v. 11, n. 2, p. 576-600.

RATHKE, Julia. Achieving comparability of secondary data. In: GSCHWEND, Thomas; SCHIMMELFENNIG, Frank. Research design: how to practice what they preach. England: British Library, 2011.

REZENDE, Flávio da Cunha. A “nova metodologia qualitativa” e as condições essenciais de demarcação entre desenhos de pesquisa na ciência política comparada. In: Revista Política Hoje, 2011, v. 20, n. 1, p. 218 - 252.

SCHIMMELFENNIG, Frank. Research design: how to practice what they preach. England: British Library, 2011.

SHUMWAY, Robert H.; STOFFER, David S. Time series analysis and its applications with $\mathbf{R}$ examples. London: Springer International Publishing AG, 2017. 
TREU, Tiziano. Labour law and sustainable development. In: Labour Law and Social Security in the Americas: 10th American Regional Congress of the International Society for Labour and Social Security law. G Giappichelli Editore, 2018.

VERMA, Anil. Labour Regulation and Jurisdictional Competitiveness, Investment, and Business Formation: A Review of the Mechanisms and Evidence. Toronto: Ontario Ministry of Labour, 2016.

Recebido em: 10.02.2019 / Revisões requeridas em: 28.03.2020 / Aprovado em: 05.06.2020 / Publicado em: 11.08.2020

\section{COMO FAZER REFERÊNCIA AO ARTIGO (ABNT):}

PINTO, Eduardo Régis Girão de Castro; GOMES, Ana Virgínia Moreira. Os efeitos do contrato intermitente na criação de novos postos de trabalho formal: uma análise de dados no estado do Ceará. Revista Eletrônica do Curso de Direito da UFSM, Santa Maria, RS, v. 15, n. 2, e36822, maio/ago. 2020. ISSN 1981-3694. DOI: http://dx.doi.org/10.5902/1981369436822. Disponível em: https://periodicos.ufsm.br/revistadireito/article/view/36822 Acesso em: dia mês. ano.

Direitos autorais 2020 Revista Eletrônica do Curso de Direito da UFSM

Editores responsáveis: Rafael Santos de Oliveira e Angela Araujo da Silveira Espindola

Esta obra está licenciada com uma Licença Creative Commons Atribuição-NãoComercial-SemDerivações 4.0 Internacional.

\section{SOBRE OS AUTORES}

EduARdo RÉGIS GIRÃo de CASTRo PINTO

Doutorando em Direito Constitucional pela Universidade de Fortaleza (2018). Possui graduação em Direito pela Universidade de Fortaleza (1999) e mestrado em Direito Constitucional pela Universidade de Fortaleza (2009). Professor de direito civil, na graduação e na pós-graduação lato sensu da Universidade de Fortaleza (UNIFOR), foi assessor de desembargador da $2 a$ Câmara de Direito Privado do Tribunal de Justiça do Estado do Ceará. Assessor Jurídico da Corregedoria-Geral de Justiça do Estado do Ceará. Foi Coordenador do Projeto de Pesquisa Processo Civil e Proteção da Pessoa nas Relações Privadas - PROCIP (Cnpq/UNIFOR). Pesquisador Líder do Projeto Pesquisa Empírica em Direito (UNIFOR). Professor no Curso de Pós-Graduação da Escola Superior de Magistratura do Ceará - ESMEC. Tem experiência na área de Direito, com ênfase em Direito CivilConstitucional, atuando principalmente nos seguintes temas: direito civil e processual civil, direito do consumidor, direitos culturais e direitos fundamentais.

\section{ANA VIRGínIA MOREIRA GOMES}

Ana Virginia Moreira Gomes é professora do Programa de Pós-Graduação em Direito Constitucional e do Curso de Direito da Universidade de Fortaleza. Possui graduação em Direito pela Universidade Federal do Ceará (1994), LL.M na Faculdade de Direito da University of Toronto (2009), doutorado em Direito pela Universidade de São Paulo (2000) e Pós-Doutorado na School of Industrial and Labor Relations da Cornell University (2007). Foi pesquisadora no Centre for Law in the Contemporary Workplace, Queen?s University, Canadá e professora adjunta na Ted Rogers School of Management, Ryerson University, Canadá. Ana Virginia Moreira Gomes coordena o Núcleo de Estudos em Direito do Trabalho e Seguridade Social na Universidade de Fortaleza. Sua pesquisa atual trata de questões pertinentes às áreas de direito do trabalho, direito internacional e direitos humanos. Seu trabalho se concentra em temas relacionados ao direito sindical, trabalho precário e vulnerável e direitos fundamentais do trabalho. 